\section{(A) Check for updates}

Cite this: Dalton Trans., 2019, 48, 673

\title{
Neptunium(Iv)-hydroxamate complexes: their speciation, and kinetics and mechanism of hydrolysis
}

\author{
S. Edwards, ${ }^{a}$ F. Andrieux, ${ }^{a}$ C. Boxall, (id $*^{a}$ M. J. Sarsfield, ${ }^{b}$ R. J. Taylor ${ }^{b}$ and \\ D. Woodhead ${ }^{\mathrm{b}}$
}

\begin{abstract}
Simple hydroxamic acids such as acteohydroxamic acid (AHA) have been identified as suitable reagents for the control of Pu and $\mathrm{Np}$ in advanced separation processes for nuclear fuel reprocessing such as the Advanced PUREX or UREX based recycle processes, due to their ability to strip the tetravalent form of $\mathrm{Pu}$ and $\mathrm{Np}$ from tri-butyl phosphate into nitric acid. However, both free and metal bound hydroxamates are known to undergo acid catalysed hydrolysis at low $\mathrm{pH}$, the kinetics of which must be characterised before implementation of PUREX/UREX based reprocessing flowsheets. In support of this implementation, a comprehensive thermodynamic and kinetic model that describes both the complex speciation and hydrolysis of AHA in the presence of $\mathrm{Np}$ (Iv) has been developed. The model has two unique features: (i) in the case of the hydrolysis reaction kinetics, the model includes the hydrolysis of not only free AHA but also both the mono- and bishydroxamato- $\mathrm{Np}$ (Iv) complexes; (ii) for the associated speciation calculations, the model explicitly includes the ionic strength dependence of not only the mono- and bishydroxamato$\mathrm{Np}$ (Iv) complexes but also the mono- and bisnitrato neptunium(IV) and monohydroxoneptunium(IV) complexes. For the latter three species, respective SIT coefficients of $\Delta \varepsilon_{1, \mathrm{NO}_{3}}=-0.13 \pm 0.03 \mathrm{~kg} \mathrm{~mol}^{-1}$, $\log _{10} \beta_{1, \mathrm{NO}_{3}}^{0}=1.79 \pm 0.14, \Delta \varepsilon_{2, \mathrm{NO}_{3}}=-0.37 \pm 0.13 \mathrm{~kg} \mathrm{~mol}^{-1}, \log _{10} \beta_{2, \mathrm{NO}_{3}}^{0}=2.29 \pm 0.64 \Delta \varepsilon_{1, \mathrm{OH}}=$ $-0.36 \mathrm{~kg} \mathrm{~mol}^{-1}$ and $\log _{10} K_{1, \mathrm{OH}}^{0}=-1.23$ were also determined. Using experimental data from a series of kinetic studies on the $\mathrm{Np}(\mathrm{IV})-\mathrm{AHA}$ system, this model has been used to determine the rate constants for hydrolysis of mono- and bis-acetohydroxamatoneptunium(Iv) at $25{ }^{\circ} \mathrm{C}$ for the first time. These were found to be $3.5 \times 10^{-5} \pm 2.5 \times 10^{-5} \mathrm{dm}^{3} \mathrm{~mol}^{-1} \mathrm{~s}^{-1}$ and $1.9 \times 10^{-3} \pm 1.3 \times 10^{-3} \mathrm{dm}^{3} \mathrm{~mol}^{-1} \mathrm{~s}^{-1}$, respectively. Comparison of these values with the rate constants for hydrolysis of free AHA indicates that complexation of $\mathrm{AHA}$ with $\mathrm{Np}$ (Iv) increases the rate of hydroxamate hydrolysis - an observation that we attribute to the electron withdrawing effect of the metal centre within the Np(Iv)-AHA complex increasing the susceptibility of the AHA carbonyl carbon to nucleophilic attack, the accepted first step in its mechanism of hydrolysis.
\end{abstract}

Received 29th May 2018, Accepted 29th November 2018 DOI: $10.1039 / \mathrm{c} 8 \mathrm{dt} 02194 \mathrm{e}$ rsc.li/dalton can also be a useful resource, as target material for $\mathrm{Pu}-238$ production for use as a power source in space missions.

Simple hydroxamic acids (XHAs) such as formo- and acetohydroxamic acids (FHA and AHA, example structure in Scheme 1), are salt-free, hydrophilic organic compounds, which act as bidentate $\mathrm{O}, \mathrm{O}$ donor ligands with affinities for 'hard' cations such as $\mathrm{Fe}^{3+}, \mathrm{Np}^{4+}$ and $\mathrm{Pu}^{4+}$ with which they form 5 -membered chelate rings. ${ }^{3-6}$ They have been used as uranium and plutonium in the first extraction stage of the PUREX process with the remainder routed to the highly active waste stream. Control of neptunium thus adds significantly to complexity and waste volumes of PUREX reprocessing. ${ }^{2} \mathrm{~Np}-237$

\footnotetext{
${ }^{a}$ Engineering Department, Lancaster University, Lancaster, Lancashire, LA1 4YW, UK. E-mail: c.boxall@lancaster.ac.uk

${ }^{b}$ National Nuclear Laboratory, Central Laboratory, Sellafield, Cumbria, CA20 1PG, $U K$
}<smiles>CC(=O)NO</smiles>

Scheme 1 Acetohydroxamic acid. 
enzyme inhibitors, ${ }^{7}$ soil enhancers, ${ }^{8}$ antimicrobials, ${ }^{9}$ DNA cleavers ${ }^{10}{ }^{10}$ spectrophotometric reagents for the determination of metal ions ${ }^{11}$ as well as in drug delivery systems ${ }^{12}$ and ion exchange applications. ${ }^{13}$ In the environment, hydroxamates are used by fungi in the sequestration of iron from soil. ${ }^{14-18}$

These ligands are also redox active capable of rapidly reducing $\mathrm{Np}(\mathrm{vI})$ to $\mathrm{Np}(\mathrm{v})^{19,20}$ and we have observed the slow reduction of $\mathrm{Pu}(\mathrm{IV})$ ions by $\mathrm{FHA}$ and $\mathrm{AHA} .{ }^{21,22}$ Their ability to efficiently strip tetravalent actinides from the PUREX solvent ( $30 \%$ tributyl phosphate in odourless kerosene - TBP/OK), however, is due to the strong hydrophilic complexes formed. ${ }^{23,24}$ Consequently, these simple reagents have been identified for use in advanced nuclear fuel cycles based on e.g. Advanced PUREX or UREX reprocessing, wherein recycling of neptunium and other minor actinides for transmutation or as fuel has been suggested. ${ }^{25}$

FHA and AHA are known to undergo acid catalysed hydrolysis in nitric acid to form hydroxylamine and the parent carboxylic acid, $\mathrm{XCOOH}$, in accordance with: ${ }^{22,26}$

$$
\mathrm{XHA}+\mathrm{H}_{3} \mathrm{O}^{+} \stackrel{k_{0}}{\longrightarrow} \mathrm{XCOOH}+\mathrm{NH}_{3} \mathrm{OH}^{+}
$$

The hydrolysis of free hydroxamates in acidic solution is well characterized, their kinetics obeying the Arrhenius relationship given below ${ }^{27}$ where for FHA and AHA, respectively, $A$, the pre-exponential factor, is $9.09 \times 10^{9}$ and $3.22 \times 10^{9}$ $\mathrm{dm}^{3} \mathrm{~mol}^{-1} \mathrm{~s}^{-1}$ and $E_{\mathrm{A}}$, the activation energy, is 77.3 and $79.9 \mathrm{~kJ} \mathrm{~mol}^{-1}$.

$$
-\frac{d[\mathrm{XHA}]}{\mathrm{d} t}=A e^{\frac{-E_{A}}{R T}}[\mathrm{XHA}]\left[\mathrm{H}_{3} \mathrm{O}^{+}\right]
$$

Hydrolysis of metal bound hydroxamates occurs at different rates, which may impact negatively on an Advanced PUREX process by decomposing the ligand during the process, so diminishing achievable separation factors. Previous work has shown that at $25{ }^{\circ} \mathrm{C}$ hydrolysis of the $1: 1$ iron(III)-AHA and $1: 1 \mathrm{~Np}(\mathrm{Iv})-\mathrm{FHA}$ complexes occurs with second order rate parameters of $5.0 \times 10^{-4}$ and $1.0 \times 10^{-5} \mathrm{dm}^{3} \mathrm{~mol}^{-1} \mathrm{~s}^{-1}$ respectively. Preliminary studies of the $\mathrm{Pu}(\mathrm{Iv})-\mathrm{XHA}$ system show that the $1: 1$ complex is slowly reduced to free $\mathrm{Pu}(\mathrm{III})$ by hydroxylamine. ${ }^{21,22}$ An understanding of these processes is vital if they are to be controlled within the design of any Advanced PUREX and/or UREX process.

To this end, we have used UV-visible and near-IR electronic absorption spectrophotometry to both study experimentally and model for the first time the kinetics of the hydrolysis of the Np(Iv)-AHA system in nitrate media. As well as hydroxamate complexes, neptunium(rv) is known to form nitrato complexes in the presence of nitrate ions, the formation of which may influence $\mathrm{Np}$ (Iv)-AHA complexation and thus the rate of hydrolysis of the hydroxamate. Therefore, both Np(Iv)-AHA and $\mathrm{Np}(\mathrm{rv})$-nitrate complexation needed to be incorporated into our kinetic model. However, the thermodynamic stability constants for the mono- and bis-hydroxamatoneptunium(Iv) complexes are unavailable whilst the conditional stability constants are only known under one set of ionic strength con- ditions (specifically $I=2 \mathrm{~mol} \mathrm{\textrm {dm } ^ { - 3 }}$ at $\left.295 \mathrm{~K}\right)^{23,28}$ - thus requiring us to work with conditional stability and equilibrium constants throughout. Whilst the dependencies of the conditional stability constants on ionic strength for the Np(Iv)-AHA complexes are unavailable, a review of available literature data has allowed us to derive such dependencies for the nitrato neptunium(rv) complexes using Specific ion Interaction Theory (SIT theory). ${ }^{29}$ Such an approach was also used by Lemire et al. in their critical review and analysis of $\log _{10} \beta$ data for, inter alia, $\mathrm{Np}(\mathrm{Iv})-\mathrm{F}^{-}, \mathrm{Np}(\mathrm{Iv})-\mathrm{NO}_{3}{ }^{-}, \mathrm{Np}(\mathrm{vI})-\mathrm{CO}_{3}{ }^{2-}, \mathrm{Pu}(\mathrm{Iv})-\mathrm{Cl}^{-}$and $\mathrm{Pu}(\mathrm{Iv})-$ $\mathrm{NO}_{3}{ }^{-}$complexes. ${ }^{30}$ For consistency, we have employed the same approach here. Therefore, our kinetic model includes not only the $\mathrm{Np}\left(\mathrm{NO}_{3}\right)^{3+}$ and $\mathrm{Np}\left(\mathrm{NO}_{3}\right)_{2}{ }^{2+}$ complexes but also, again for the first time, the effect of ionic strength on the concentrations of these complexes.

Thus, in this paper, we have built a numerical model in the process modelling software, gPROMS, to determine rates of hydrolysis of the mono- and bis-hydroxamatoneptunium(rv) complexes. We have included ionic strength dependent concentrations of $\mathrm{NpNO}_{3}{ }^{3+}$ and $\mathrm{Np}\left(\mathrm{NO}_{3}\right)_{2}{ }^{2+}$ using SIT theory.

\section{Experimental}

$\mathrm{Np}(\mathrm{Iv})$ aqueous stock solutions were prepared as described previously. ${ }^{31}$ Specifically, neptunium stock solutions in nitric acid were prepared from dissolution of $\mathrm{NpO}_{2}$ in strong nitric acid under reflux. Concentrations of total neptunium in the resultant stock were confirmed by gamma spectroscopy, calibrated against a neptunium standard. Valence conditioning to form a $\mathrm{Np}$ (Iv) stock was then achieved by electrochemical conditioning $(-0.35 \mathrm{~V}$ vs. $\mathrm{Ag} / \mathrm{AgCl}$ using a platinum gauze working electrode) or by addition of a substantial excess of $\mathrm{Fe}(\mathrm{II})\left(\mathrm{FeCl}_{2}\right)$. In the latter case, $\mathrm{Np}(\mathrm{Iv})$ solution was purified from $\mathrm{Fe}$ and $\mathrm{Cl}$ ions by solvent extraction into $30 \%$ tributyl phosphate (TBP) in odourless kerosene and backwashing into $\mathrm{HNO}_{3}$. In such solutions, $\mathrm{Np}$ is predominantly present as $\mathrm{Np}(\mathrm{Iv})$ with small amounts of $\mathrm{Np}(\mathrm{v})$, the exact proportions being dependent on factors including acidity and standing time. With $\mathrm{Np}(\mathrm{v})$, its characteristic bands at $979 \mathrm{~nm}$ and $1100 \mathrm{~nm}$ in its UV-visible, near-infra-red (near IR) electronic absorption spectrum (EAS) $\left(\varepsilon=369 \mathrm{dm}^{3} \mathrm{~mol}^{-1} \mathrm{~cm}^{-1}\right.$ and $24 \mathrm{dm}^{3} \mathrm{~mol}^{-1} \mathrm{~cm}^{-1}$ respectively in nitric acid media ${ }^{32}$ ) enable sub-millimolar $\mathrm{Np}(\mathrm{v})$ concentrations to be accurately resolved by spectrophotometry. Thus, $\mathrm{Np}(\mathrm{v})$ was quantified using EAS throughout the experiments described below and, from an averaging of the concentrations calculated using the bands at both $979 \mathrm{~nm}$ and $1100 \mathrm{~nm}$, was found to be $\sim 11 \%$ of total Np present. The implications of this for the speciation and kinetic run studies presented herein are considered during the discussion of Fig. 9 and 10 below.

All other reagents including $\mathrm{HNO}_{3}(70 \%$, AnalaR, $\mathrm{BDH}$ Chemicals Ltd, UK) and AHA (Sigma-Aldrich Ltd, UK) were obtained from suppliers at the highest available purity and used as received. AHA was stored at $4{ }^{\circ} \mathrm{C}$ to prevent decomposition; solutions were prepared immediately prior to use in 


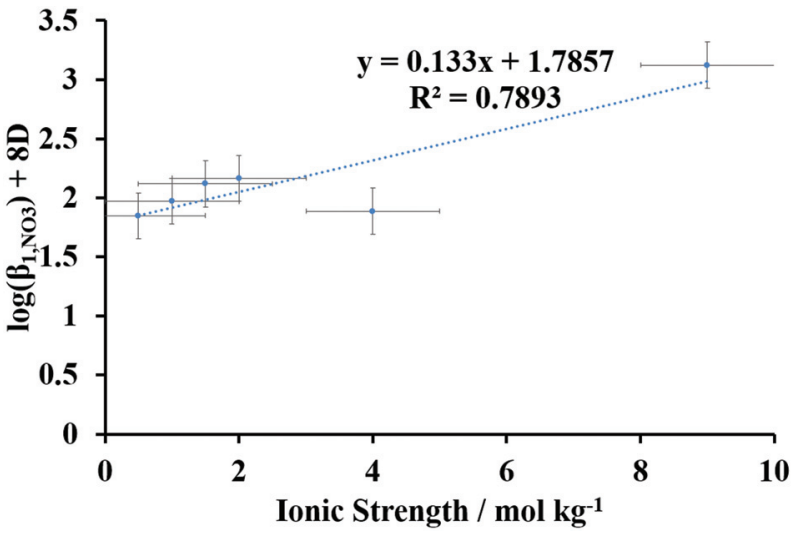

Fig. 1 Plot of literature values of $\log _{10}\left(\beta_{1, \mathrm{NO}_{3}}\right)+8 D$ vs. ionic strength for $\mathrm{NpNO}_{3}{ }^{3+}$ complex, plotted using the data of Table 2 in the temperature range $293-298 \mathrm{~K}$.

order to prevent hydrolysis, by room temperature dissolution of a weighed portion into distilled water.

UV-visible, near IR EAS were recorded using PerkinElmer Lambda 19 or 900 spectrophotometers coupled by fibre optics to an external sample compartment for remote safe analysis of the $\alpha$-active radioisotope ${ }^{237} \mathrm{~Np}$. Both instruments had a spectral resolution/data interval of $1 \mathrm{~nm}$. Note that in all figures containing neptunium spectra, the individual spectra have been offset for clearer comparison.

Solutions for the kinetic experiments of $\mathrm{Np}$ (Iv)-AHA complex stability were prepared by mixing aliquots of $\mathrm{Np}$ (Iv) stock, $\mathrm{HNO}_{3}$ and AHA directly into an optical cuvette of pathlength $1 \mathrm{~cm}$; the complexant was added last. During the kinetic absorbance measurements, the spectrometer was set to scan the range $600-1300 \mathrm{~nm}$ at variable time intervals. All kinetic runs were recorded in the narrow temperature range of 297-298 K with the temperature being maintained by a water flow controlled Ocean Optics fibre optic cell holder. The temperature of the solution was checked using a thermocouple at the end of each experiment.

The main peaks of interest in the spectra reported below are those due to $\mathrm{Np}(\mathrm{v})$ at 979 and $1100 \mathrm{~nm}$ (vide supra) and the compound feature centred at $732 \mathrm{~nm}$ associated with the $\mathrm{Np}$ (Iv)-hydroxamate complexes. ${ }^{4}$ All three peaks were corrected to account for baseline shifts between experiments. For the strong $\mathrm{Np}(\mathrm{v})$ peak at $979 \mathrm{~nm}$ and the weaker peak at $1100 \mathrm{~nm}$, this simply involved measuring the absorbances at 979 and $1100 \mathrm{~nm}$ with respect to an extrapolated baseline drawn between two reference points: the absorbance values at 640 and $1050 \mathrm{~nm}$ where the molar absorptivities due to free $\mathrm{Np}$ (Iv), free $\mathrm{Np}(\mathrm{v})$ and $\mathrm{Np}(\mathrm{rv})$-AHA are near zero.

Due to the more complex nature of the feature at $732 \mathrm{~nm}$, we used the same baseline correction methodology reported in an earlier communication ${ }^{4}$ and a subsequent paper by Taylor et $a .^{23}$ This involved drawing a line between the absorbances at two reference points much closer to the feature maximum and measuring the absorbance at $732 \mathrm{~nm}$ with respect to that line. In this case, the two points used were the absorbance values at $640 \mathrm{~nm}$ and $775 \mathrm{~nm}$.

As discussed above, the molar absorptivities of $\mathrm{Np}(\mathrm{Iv}), \mathrm{Np}(\mathrm{v})$ and $\mathrm{Np}$ (Iv)-AHA complexes are near zero at $640 \mathrm{~nm}$ and so do not change as the speciation changes between the free $\mathrm{Np}$, $\mathrm{Np}$-nitrate and Np-AHA species. In contrast, both the Np(Iv)$\mathrm{HNO}_{3}$ and $\mathrm{Np}$ (Iv)-AHA systems studied here exhibit non-zero, but small, absorptivities at $775 \mathrm{~nm}$. For freshly made solutions of these systems, absorptivities were found to depend principally on $\left[\mathrm{HNO}_{3}\right]$; specifically the absorbance at $775 \mathrm{~nm}$, measured with respect to that at $640 \mathrm{~nm}$, was found to be $0.011 \pm 0.001$ and $0.016 \pm 0.003$ at 1 and $3 \mathrm{~mol} \mathrm{dm}{ }^{-3} \mathrm{HNO}_{3}$ respectively. This gives rise to a small uncertainty in baseline between acidities of 0.003 absorbance units at $732 \mathrm{~nm}$, which translates to an average uncertainty in the baseline-subtracted peak absorbance at $732 \mathrm{~nm}$ of just $2.3 \%$ - justifying the use of this baseline correction for the speciation studies described later where the $732 \mathrm{~nm}$ peak absorbance is measured from freshly made solutions.

Consequently, and again for reasons of consistency with previous studies, ${ }^{4,23}$ the same baseline correction method was also used for the $732 \mathrm{~nm}$ peak absorbance during kinetic run studies of Fig. 10 below. In this instance, we compare the absorbances measured at $775 \mathrm{~nm}$, again with respect to that at $650 \mathrm{~nm}$, at the start and end of the runs. In this instance, the absorbance at $775 \mathrm{~nm}$, measured with respect to that at $650 \mathrm{~nm}$, was found to change by an average of $0.009 \pm 0.012$ over all kinetic runs. This gives rise to a small uncertainty in baseline from the beginning to the end of a run of 0.006 absorbance units at $732 \mathrm{~nm}$, which translates to an average uncertainty in the baseline-subtracted peak absorbance at $732 \mathrm{~nm}$ of just $5.6 \%$ of the absorbance value at the end of each run - justifying the use of this baseline correction for the kinetic runs described later.

Two different software packages have been used to generate and model the results presented in this paper. Firstly, HySS is free software that is widely used for simulating titration curves and calculating speciation diagrams (available at http://www. hyperquad.co.uk/hyss.htm). When calculating speciation diagrams, stability constants for each species and the added reagent concentration ranges are entered into the user interface. HySs performs a mass balance on each of the reagents solving a set of linear equations written in a Fortran subroutine called by the HySS program. ${ }^{33}$ The software is capable of performing calculations for an unlimited number of reagents and equilibria, as well as when solid precipitate is present in solution. The calculated results can be copied to Microsoft Excel to plot customised diagrams, such as those presented in Fig. 5-8, vide infra.

Secondly, gPROMS (General PROcess Modelling System, Process Systems Enterprise, UK) is an industry standard software platform for creating first principles process models coupled with experimental data. It has been used to determine reaction kinetics from experimental data for a wide range of chemical processes both heterogeneous (e.g. solvent extraction, ${ }^{34}$ solid-liquid adsorption ${ }^{35}$ and crystallization ${ }^{36}$ ) and 
homogeneous (e.g. enzyme catalyzed addition reactions ${ }^{37}$ ). Here we employed gPROMs to determine the reaction kinetics of the homogeneous complexation/hydrolysis reactions in the $\mathrm{Np}$ (Iv)-AHA system from speciation and kinetic run data. Rate constants were determined using the parameter estimation facility of gPROMS. This facility uses a maximum likelihood formulation to determine parameter values and performs statistical analysis on the results. ${ }^{38}$ Experimental results are imported into gPROMS in order to perform parameter estimation.

The gPROMS objective function for finding parameters is the maximum likelihood formulation ${ }^{39}$ given by the equation below. In this, $N$ is the total number of measurements taken during all the experiments; $\theta$ is the set of model parameters to be estimated; NE is the number of experiments performed; $\mathrm{NV}_{i}$ is the number of variables measured in the $i^{\text {th }}$ experiment; $\mathrm{NM}_{i j}$ is the number of measurements of the $j^{\text {th }}$ variable in the $i^{\text {th }}$ experiment; $\sigma_{i j k}^{2}$ is the variance of the $k^{\text {th }}$ measurement of variable $j$ in experiment $i ; \overline{z_{i j k}}$ is the $k^{\text {th }}$ measured value of variable $j$ in experiment $I ; z_{i j k}$ is the $k^{\text {th }}$ predicted value of variable $j$ in experiment $i$.

$$
\begin{aligned}
\Phi= & N / 2 \ln (2 \pi) \\
& +1 / 2 \min _{\theta}\left(\sum_{i=1}^{N E} \sum_{j=1}^{N V_{i}} \sum_{k=1}^{N M_{i j}} \ln \left[\left(\sigma_{i j k}^{2}+\frac{\left(\overline{z_{i j k}}-z_{i j k}\right)^{2}}{\sigma_{i j k}^{2}}\right]\right)\right.
\end{aligned}
$$

This objective function has the advantage of being able to determine multiple parameters simultaneously and give statistical analysis of the results. Minimisation of the maximum likelihood formulation is achieved using the MAXLKHD solver of gPROMS. Note that the fitting parameters must be given pre-determined bounds found by preliminary investigation.

\section{Results and discussion}

The dynamics of hydrolysis of the metal-AHA system in acidic media such as $\mathrm{HNO}_{3}$ and $\mathrm{HClO}_{4}$ are complicated by metalAHA complex speciation and competitive complexation with $\mathrm{NO}_{3}{ }^{-}$and - potentially at some of the lower acidities employed in this study (see Fig. 9 below) $-\mathrm{OH}^{-}$anions. Thus in this section, we extend metal-hydroxamate-pH speciation diagrams from our previous paper investigating $\mathrm{Np}$ (Iv)-FHA hydrolysis ${ }^{4}$ to include ionic strength dependent concentrations of $\mathrm{Np}$ (Iv) mono and bisnitrato and monohydroxide complexes.

Sarsfield et al. have published a model of the extraction of $\mathrm{Np}$ (Iv)-AHA complexes into TBP. ${ }^{28}$ In this, they note that no evidence has yet been reported for Np(Iv) mixed ternary complexes of AHA in the aqueous phase with either nitrate or $\mathrm{OH}^{-}$ ions, even though such ternary complexes seem probable. Consequently, they ignore ternary complexes in their model and assume that all aquo-species can be modelled in terms of individual nitrate, hydroxyl, and AHA complexes of $\mathrm{Np}$ (IV). Here we adopt a similar approach for the same reasons.

The conditional stability constants for the formation of the $\mathrm{Np}(\mathrm{Iv})$-AHA complexes in non-complexing perchlorate media are only available at one temperature and ionic strength, $295 \mathrm{~K}$ and $2.0 \mathrm{~mol} \mathrm{~kg}{ }^{-1} \cdot{ }^{23}$ Similarly, conditional stability constant values for the hydroxyl complexes of $\mathrm{Np}$ (Iv) are also only available at one temperature, $298 \mathrm{~K}$, although at a slightly wider range of ionic strengths, 1 and $2 \mathrm{~mol} \mathrm{~kg}{ }^{-1} \cdot{ }^{30}$ In contrast, values are available at a range of ionic strengths for the AHA acid dissociation constant ${ }^{28}$ (required to convert the $\mathrm{Np}$ (Iv)AHA complex stability constants into stepwise equilibrium constants $\mathrm{Np}$ (Iv)-AHA complex formation) and the stability constants for the formation of the $\mathrm{Np}(\mathrm{Iv})-\mathrm{NO}_{3}$ complexes, ${ }^{30}$ thus allowing SIT theory to be used to derive relationships describing the dependencies of these constants on ionic strength. However, none of these constants have significantly large numbers of values reported at a single temperature values of the AHA dissociation constant are also reported over a temperature range of 295-298 K, whilst those of the Np(IV)nitrate complex stability constants are reported at two closely placed temperatures, 293 and $298 \mathrm{~K}$. So as to maximize the number of data points used in SIT analyses of the AHA dissociation constant and the mononitrato neptunium(Iv) complex stability constant, Sarsfield et al. ${ }^{28}$ and Lemire et al. ${ }^{30}$ respectively use all dissociation/stability constants reported in the temperature ranges just cited. This results in SIT relationships describing the ionic strength dependencies for these constants that can be considered to apply at 295-298 K for the AHA dissociation constant and at 293-298 $\mathrm{K}$ for the mononitrato neptunium(Iv) complex stability constant. Advantageously, these temperature ranges encompass the temperatures at which the conditional stability constants for the formation of the $\mathrm{Np}$ (Iv)-AHA and $\mathrm{Np}$ (Iv)- $\mathrm{OH}^{-}$complexes are reported, 295 and $298 \mathrm{~K}$ respectively. Accordingly, we have used these data to calculate metal-hydroxamate-nitrate- $\mathrm{pH}$ speciation diagrams for all binary complexes formed in the $\mathrm{Np}$ (Iv)-AHA- $\mathrm{HNO}_{3}$ system - said diagrams explicitly accounting for the ionic strength dependent concentrations of the $\mathrm{Np}(\mathrm{Iv})$ mono- and bisnitrato and monohydroxide complexes. Within the constraints of available data, these diagrams may be considered to be valid only for 295-298 K; consequently, all experimental kinetic runs reported here (Fig. 9-11, vide infra) were also recorded in this temperature range.

The metal-hydroxamate-nitrate-pH speciation diagrams presented in this paper are then calculated as follows. First, speciation diagrams are calculated for the $\mathrm{Np}(\mathrm{Iv})-\mathrm{NO}_{3}$ system in the absence of AHA in the temperature range 293-298 $\mathrm{K}$ as a function of total nitric concentration using HySs (hyperquad simulation and speciation) software package. Calculations are then extended to calculate the speciation of the Np(rv)-AHA$\mathrm{NO}_{3}$ system at $295 \mathrm{~K}$ as a function of total AHA concentration expressed as pHL where $\mathrm{pHL}=-\log _{10}[\mathrm{AHA}]$. The process is described in detail in the next section.

\section{Speciation and kinetic modelling of metal-hydroxamic acid systems}

$\mathrm{Np}$ (Iv) forms hydroxamate complexes in ratios $1: 1$ to $3: 1$, AHA : metal. ${ }^{4}$ Conditional stability constants have been obtained at $295 \mathrm{~K}$ in non-complexing perchlorate media at an 
ionic strength, $I$, of $2.0 \mathrm{~mol} \mathrm{~kg}^{-1}$ for the equilibria given in eqn (2a)-(2c). ${ }^{23}$ These conditional stability constants are as follows:

$$
\mathrm{L}^{-}+\mathrm{Np}^{4+} \stackrel{\beta_{1}}{\longleftrightarrow} \mathrm{NpL}^{3+}
$$

where

$$
\begin{aligned}
& \beta_{1}=\frac{\left[\mathrm{NpL}^{3+}\right]}{\left[\mathrm{Np}^{4+}\right]\left[\mathrm{L}^{-}\right]}=6.76 \times 10^{12} \mathrm{dm}^{3} \mathrm{~mol}^{-1} \\
& 2 \mathrm{~L}^{-}+\mathrm{Np}^{4+} \stackrel{\beta_{2}}{\longleftrightarrow} \mathrm{NpL}_{2}^{2+}
\end{aligned}
$$

where

$$
\begin{aligned}
\beta_{2}= & \frac{\left[\mathrm{NpL}_{2}^{2+}\right]}{\left[\mathrm{Np}^{4+}\right]\left[\mathrm{L}^{-}\right]^{2}}=9.12 \times 10^{22} \mathrm{dm}^{6} \mathrm{~mol}^{-2} \\
& 3 \mathrm{~L}^{-}+\mathrm{Np}^{4+} \stackrel{\beta_{3}}{\longleftrightarrow} \mathrm{NpL}_{3}^{+}
\end{aligned}
$$

where

$$
\beta_{3}=\frac{\left[\mathrm{NpL}_{3}^{+}\right]}{\left[\mathrm{Np}^{4+}\right]\left[\mathrm{L}^{-}\right]^{3}}=1.15 \times 10^{30} \mathrm{dm}^{9} \mathrm{~mol}^{-3}
$$

where $\mathrm{HL}$ is AHA; $\mathrm{L}^{-}$is the deprotonated conjugate base. As discussed above, literature values for $\beta_{1}$ to $\beta_{3}$ are limited to those given in eqn (2a)-(2c) - meaning that the dependence on ionic strength, $I$, of these stability constants is currently unavailable. Also as discussed above, in contrast the ionic strength dependence of the acid dissociation constant for AHA, $K_{\mathrm{a}, \mathrm{AHA}}$, can be calculated using SIT Theory. ${ }^{35}$ This is of relevance as it determines the availability of $\mathrm{L}^{-}$to participate in the complex formation reactions given in eqn (2a)-(2c). Sarsfield et al. have obtained such a dependence by performing a SIT theory-based fit to literature data reported in the temperature range $295-298 \mathrm{~K}^{28}$

$$
\begin{aligned}
\mathrm{p} K_{\mathrm{a}, \mathrm{AHA}} & =-\log _{10} K_{\mathrm{a}, \mathrm{AHA}} \\
& =-\log _{10} K_{\mathrm{a}, \mathrm{AHA}}^{0}-\Delta z_{i}^{2} D+\Delta \varepsilon I \\
& =9.54-2 D-0.03 I
\end{aligned}
$$

where

$$
D=\frac{(0.51 \sqrt{I})}{(1+1.5 \sqrt{I})} \text { at } 294-298 \mathrm{~K}
$$

and

$$
I=\frac{1}{2} \sum_{i} m_{i} z_{i}^{2}
$$

where $K_{\mathrm{a}, \mathrm{AHA}}^{0}$ is the acid dissociation constant for AHA at infinite dilution; $\varepsilon$ is the ion interaction coefficient and $\Delta \varepsilon=$ $\sum \varepsilon$ (products) $-\sum \varepsilon$ (educts); $D$ is the Debye-Hückel term; $I$ is the molal ionic strength; $m_{i}$ is the molal concentration of species $i ; z_{i}$ is the charge of species $i ; \Delta z_{i}^{2}$ is the sum of the squared charge of the reaction products (in this case the hydronium ion and the deprotonated conjugate base of AHA) minus the sum of the squared charge of the educts/reactants (undissociated AHA). For a given ionic strength, eqn (3a) may be used to convert the conditional stability constants of eqn (2a)-(2c) into conditional equilibrium constants $K_{1}, K_{2}$ and $K_{3}$ for the equilibria given in eqn (4a)-(4c) as follows: ${ }^{23}$

$$
\mathrm{HL}+\mathrm{Np}^{4+} \stackrel{K_{1}}{\longleftrightarrow} \mathrm{NpL}^{3+}+\mathrm{H}^{+}
$$

where

$$
\begin{aligned}
K_{1}= & \frac{\left[\mathrm{NpL}^{3+}\right]\left[\mathrm{H}^{+}\right]}{\left[\mathrm{Np}^{4+}\right][\mathrm{HL}]}=K_{\mathrm{a}, \mathrm{AHA}} \beta_{1} \\
& \mathrm{HL}+\mathrm{NpL}^{3+} \stackrel{K_{2}}{\longleftrightarrow} \mathrm{NpL}_{2}^{2+}+\mathrm{H}^{+}
\end{aligned}
$$

where

$$
\begin{aligned}
K_{2}= & \frac{\left[\mathrm{NpL}_{2}^{2+}\right]\left[\mathrm{H}^{+}\right]}{\left[\mathrm{NpL}^{3+}\right][\mathrm{HL}]}=K_{\mathrm{a}, \mathrm{AHA}} \beta_{2} / \beta_{1} \\
& \mathrm{HL}+\mathrm{NpL}_{2}^{2+} \stackrel{K_{3}}{\longleftrightarrow} \mathrm{NpL}_{3}^{+}+\mathrm{H}^{+}
\end{aligned}
$$

where

$$
K_{3}=\frac{\left[\mathrm{NpL}_{3}^{+}\right]\left[\mathrm{H}^{+}\right]}{\left[\mathrm{NpL}_{2}^{2+}\right][\mathrm{HL}]}=K_{\mathrm{a}, \mathrm{AHA}} \beta_{3} / \beta_{2}
$$

For the experiments presented later, the ionic strength is predominantly determined by the concentration of nitric acid, present in vast excess. Thus, Table 1 reports values for $K_{\mathrm{a}, \mathrm{AHA}}$, $K_{1}, K_{2}$ and $K_{3}$ at $295 \mathrm{~K}$ at the nitric acid concentrations of $0.5,1$ and $3 \mathrm{~mol} \mathrm{dm}^{-3}$ used in those experiments.

Neptunium(Iv) forms a range of weak inner sphere complexes with nitrate ions of which the mono- and bis-nitrato species are the most important in the $\mathrm{HNO}_{3}$ concentration range used in these experiments. ${ }^{41-44}$ These complexes, for which the stability constants $\beta_{1, \mathrm{NO}_{3}}$ and $\beta_{2, \mathrm{NO}_{3}}$ are given by eqn (5) and (6), would form during PUREX/UREX-based reprocessing, limiting the availability of neptunium(Iv) to complex with the hydroxamate ligand. Literature values for $\beta_{1, \mathrm{NO}_{3}}$ and $\beta_{2, \mathrm{NO}_{3}}$ are given in logarithmic form in Tables 2 and 3 as reported in the critical review of Lemire et al. ${ }^{30}$

$$
\mathrm{Np}^{4+}+\mathrm{NO}_{3} \stackrel{-\beta_{1, \mathrm{NO}_{3}}}{\longleftrightarrow} \mathrm{NpNO}_{3}{ }^{3+}
$$

where

$$
\begin{aligned}
& \beta_{1, \mathrm{NO}_{3}}=\left[\mathrm{NpNO}_{3}{ }^{3+}\right] /\left[\mathrm{Np}^{4+}\right]\left[\mathrm{NO}_{3}{ }^{-}\right] \\
& \mathrm{Np}^{4+}+2 \mathrm{NO}_{3}-\stackrel{\beta_{2, \mathrm{NO}_{3}}}{\longleftrightarrow} \mathrm{Np}\left(\mathrm{NO}_{3}\right)_{2}{ }^{2+}
\end{aligned}
$$

where

$$
\beta_{2, \mathrm{NO}_{3}}=\left[\mathrm{Np}\left(\mathrm{NO}_{3}\right)_{2}{ }^{2+}\right] /\left[\mathrm{Np}^{4+}\right]\left[\mathrm{NO}_{3}{ }^{-}\right]^{2}
$$

Table 1 Values for the conditional equilibrium constants $K_{\mathrm{a}, \mathrm{AHA}}, K_{1}, K_{2}$ and $K_{3}$ at $295 \mathrm{~K}$ for differing nitric acid concentrations (ionic strengths) calculated using eqn (2)-(4)

\begin{tabular}{llllrl}
\hline$\left[\mathrm{HNO}_{3}\right] / \mathrm{mol} \mathrm{dm}^{-3}$ & $\mathrm{p} K_{\mathrm{a}, \mathrm{AHA}}$ & $K_{\mathrm{a}, \mathrm{AHA}}$ & $K_{1}$ & \multicolumn{1}{c}{$K_{2}$} & $K_{3}$ \\
\hline 0.5 & 9.17 & $6.76 \times 10^{-10}$ & 4570 & 9.12 & 0.0085 \\
1 & 9.1 & $7.94 \times 10^{-10}$ & 5370 & 10.71 & 0.01 \\
3 & 8.96 & $1.1 \times 10^{-9}$ & 7413 & 14.79 & 0.0138
\end{tabular}


Table 2 Literature values for the stability constant $\beta_{1, \mathrm{NO}_{3}}$ of mono-nitrato neptunium(IV) in the temperature range $293-298 \mathrm{~K}$ at differing ionic strengths, obtained from the critical review of Lemire et al. ${ }^{30}$

\begin{tabular}{llll}
\hline Method & Ionic medium & Temp./K & Log $_{10} \beta_{1, \mathrm{NO}_{3}}$ \\
\hline Distribution, TTA & $0.5 \mathrm{~mol} \mathrm{dm}^{-3} \mathrm{HClO}_{4}$ & 293 & 0.45 \\
Distribution, TTA & $1 \mathrm{~mol} \mathrm{dm}^{-3} \mathrm{HClO}_{4}$ & 0.34 & 40 \\
Distribution, TTA & $1.5 \mathrm{~mol} \mathrm{dm}^{-3} \mathrm{HClO}_{4}$ & 293 & 0.36 \\
Distribution, TTA & $2 \mathrm{~mol} \mathrm{dm}^{-3} \mathrm{HClO}_{4}$ & 293 & 0.30 \\
Spectroscopic, Kinetic & $2 \mathrm{~mol} \mathrm{dm}^{-3} \mathrm{HClO}_{4}$ & 293 & 0.34 \\
Distribution, TTA & $4 \mathrm{~mol} \mathrm{dm}^{-3}\left(\mathrm{Na}_{4} \mathrm{H}\right) \mathrm{ClO}_{4}$ & 298 & -0.15 \\
Spectroscopic & $9 \mathrm{~mol} \mathrm{dm}^{-3} \mathrm{HClO}_{4}$ & 298 & 40 \\
& & 298 & 40.9
\end{tabular}

Table 3 Literature values for the stability constant of bis-nitrato neptunium(Iv), $\beta_{2, \mathrm{NO} 3}$, in the temperature range $293-298 \mathrm{~K}$ at differing ionic strengths, obtained from the critical review of Lemire et al. ${ }^{30}$

\begin{tabular}{lllll}
\hline Method & Ionic Medium & Temp./K & $\log _{10} \beta_{2, \mathrm{NO}_{3}}$ & Reference \\
\hline Distribution, TTA & $1 \mathrm{~mol} \mathrm{dm}^{-3} \mathrm{HClO}_{4}$ & 293 & 0.080 & {$[40]$} \\
Distribution, TTA & $2 \mathrm{~mol} \mathrm{dm}^{-3} \mathrm{HClO}_{4}$ & 293 & 0.18 & -0.74 \\
Distribution, TTA & $4 \mathrm{~mol} \mathrm{dm}^{-3}(\mathrm{Na}, \mathrm{H}) \mathrm{ClO}_{4}$ & 298 & {$[40]$} & {$[42]$} \\
Spectroscopic & $9 \mathrm{~mol} \mathrm{dm}^{-3} \mathrm{HClO}_{4}$ & 298 & 2.06 & {$[43]$}
\end{tabular}

Furthermore, again as mentioned above, neptunium(Iv) forms $\mathrm{NpOH}^{3+}, \mathrm{Np}(\mathrm{OH})_{2}{ }^{2+}, \mathrm{Np}(\mathrm{OH})_{3}{ }^{+}$and $\mathrm{Np}(\mathrm{OH})_{4}$ complexes. Preliminary speciation diagrams (not shown) indicate that the formation of hydroxide complexes higher than $\mathrm{NpOH}^{3+}$ is unlikely at $\mathrm{pH}<2$ and so can be neglected under the conditions used in PUREX/UREX-based reprocessing. However, the same may not be true for the $\mathrm{HNO}_{3}$ concentrations used here (0.5-3 mol dm ${ }^{-3} \mathrm{HNO}_{3}$, see Table 1 and Fig. 9 below). This is in agreement with a recent paper by Yusov et $a l .{ }^{44}$ that arrives at the same conclusion. Thus, of the $\mathrm{Np}(\mathrm{IV})-\mathrm{OH}$ species studied only the $\mathrm{NpOH}^{3+}$ complex may be present in significant quantities under the conditions studied here; the equilibrium constant, $K_{1, \mathrm{OH}}$, for the formation of the monohydroxide complex by $\mathrm{Np}^{4+}$ hydrolysis is given in eqn (7).

$$
\mathrm{Np}^{4+} \stackrel{K_{1, \mathrm{OH}}}{\longleftrightarrow} \mathrm{NpOH}^{3+}+\mathrm{H}_{3} \mathrm{O}^{+}
$$

where $K_{1, \mathrm{OH}}=\frac{\left[\mathrm{NpOH}^{3+}\right]\left[\mathrm{H}_{3} \mathrm{O}^{+}\right]}{\left[\mathrm{Np}^{4+}\right]}$

As described above, our previous speciation and kinetic modelling of the $\mathrm{Np}$ (Iv)-FHA system only considered formation of the $\mathrm{NpNO}_{3}{ }^{3+}$ complex using a conditional equilibrium constant determined in $4.0 \mathrm{~mol} \mathrm{dm}{ }^{-3} \mathrm{HClO}_{4} \cdot{ }^{4}$ Improving upon this, the models presented here have been extended to include the ionic strength dependence of the degree of complexation of the mono- and bis-nitrato and monohydroxide complexes.

To enable this, we have derived the dependencies on ionic strength of the stability constants for the neptunium(Iv) monoand bis-nitrato complexes by applying SIT theory to literature data. This has involved adapting the approach of eqn (3a), where for complex stability constants the term $\Delta z_{i}^{2}$ is now the difference in the squared charge of the complex and the complex's constituent ions, the SIT equations for $\log _{10} \beta_{1, \mathrm{NO}_{3}}$ and $\log _{10} \beta_{2, \mathrm{NO}_{3}}$ are then given by:

$$
\log _{10} \beta_{1, \mathrm{NO}_{3}}=\log _{10} \beta_{1, \mathrm{NO}_{3}}^{0}-I \Delta \varepsilon_{1, \mathrm{NO}_{3}}-8 D
$$

$$
\log _{10} \beta_{2, \mathrm{NO}_{3}}=\log _{10} \beta_{2, \mathrm{NO}_{3}}^{0}-I \Delta \varepsilon_{2, \mathrm{NO}_{3}}-14 D
$$

where $\beta_{1, \mathrm{NO}_{3}}^{0}$ and $\beta_{2, \mathrm{NO}_{3}}^{0}$ are the stability constants of monoand bis-nitrato complexes at infinite dilution, $\Delta \varepsilon_{1, \mathrm{NO}_{3}}$ and $\Delta \varepsilon_{2}$, $\mathrm{NO}_{3}$ are the respective ion interaction correction coefficients, and all other terms take their usual meanings. An analogous equation can be written for the ionic strength dependence of the formation of the neptunium(Iv) monohydroxide complex:

$$
\log _{10} K_{1, \mathrm{OH}}=\log _{10} K_{1, \mathrm{OH}}^{0}-I \Delta \varepsilon_{1, \mathrm{OH}}-6 D
$$

Values of $\Delta \varepsilon$ and $\log _{10} \beta^{0}$ for the $\mathrm{Np}(\mathrm{Iv})$-nitrate complexes were obtained by plotting values of $\left(\log _{10} \beta_{\mathrm{i}}-\Delta z^{2} D\right)$, derived from the literature data of Tables 2 and 3, against ionic strength as per eqn (8) and (9); the plot gradient is equal to $\Delta \varepsilon$ and $\log _{10} \beta^{0}$ can be obtained from its y axis intercept. Thus, Fig. 1 and 2 show plots of $\log _{10} \beta_{1, \mathrm{NO}_{3}}+8 D$ and $\log _{10} \beta_{2, \mathrm{NO}_{3}}+$ $14 D$ vs. $I$ for the data of Tables 2 and 3 respectively.

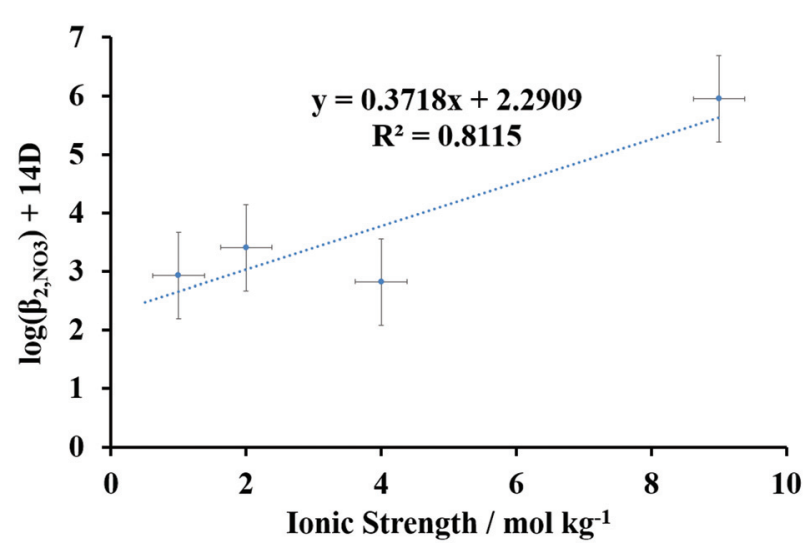

Fig. 2 Plot of literature values of $\log _{10}\left(\beta_{2, \mathrm{NO}_{3}}\right)+14 D$ vs. ionic strength for $\mathrm{Np}\left(\mathrm{NO}_{3}\right)_{2}{ }^{2+}$ complex, plotted using the data of Table 3 in the temperature range $293-298 \mathrm{~K}$. 
As can be seen from Tables 2 and 3, there are comparatively little $\log _{10} \beta$ data for the nitrate-neptunium(Iv) complexes with data for the bis-nitrato neptunium(Iv) complex being particularly sparse. Thus, as described at the beginning of section 3 , so as to maximize the number of data points used in the SIT extrapolation of Fig. 2 we have used $\log _{10} \beta_{2}, \mathrm{NO}_{3}$ data recorded at 293 and $298 \mathrm{~K}$, and at ionic strengths higher than those normally employed in SIT theory-based analyses - an approach also used by Lemire et al. in their analysis of $\log _{10} \beta$ data for nitrate and halide complexes of $\mathrm{Np}(\mathrm{Iv})$ and $\mathrm{Pu}(\mathrm{Iv}) .{ }^{30}$ For consistency, we have also employed the same approach for the $\log _{10} \beta_{1}, \mathrm{NO}_{3}$ data of Fig. 1. The linear trends observed in Fig. 1 and 2 suggest that this approach is reasonable.

The slope and intercept of the plot in Fig. 1 give values of $\Delta \varepsilon_{1, \mathrm{NO}_{3}}=-0.13 \pm 0.03 \mathrm{~kg} \mathrm{~mol}^{-1}$ and $\log _{10} \beta_{1, \mathrm{NO}_{3}}^{0}=1.79 \pm 0.14$ respectively in the temperature range 293-298 K. Despite the data point at an ionic strength of $4 \mathrm{~mol} \mathrm{~kg}^{-1}$ being an apparent outlier, these values are in good agreement with values of $\Delta \varepsilon_{1, \mathrm{NO}_{3}}=-0.09 \pm 0.05 \mathrm{~kg} \mathrm{~mol}^{-1}$ and $\log _{10} \beta_{1, \mathrm{NO}_{3}}^{0}=1.90 \pm 0.15$ obtained by Lemire et al. at $298 \mathrm{~K}$ using data over a slightly narrower ionic strength range ${ }^{30}$ - again suggesting that the approach of Fig. 1 and 2 is reasonable. The values of $\Delta \varepsilon_{1, \mathrm{NO}_{3}}$ and $\log _{10} \beta_{1, \mathrm{NO}_{3}}^{0}$ obtained from Fig. 1 are also consistent with analogous values for the mono-nitrato complexes of uranium (Iv), for which $\Delta \varepsilon_{1, \mathrm{NO}_{3}}=-0.21 \mathrm{~kg} \mathrm{~mol}^{-1}$ and $\beta^{0}{ }_{1, \mathrm{NO}_{3}}=1.47^{45,46}$ and plutonium(Iv), for which $\Delta \varepsilon_{1, \mathrm{NO}_{3}}=-0.17 \mathrm{~kg} \mathrm{~mol}^{-1}$ and $\log _{10} \beta_{1, \mathrm{NO}_{3}}^{0}=2.12 .^{47}$ From these values, it appears that $\log _{10} \beta_{1, \mathrm{NO}_{3}}^{0}$ increases across the actinide series whereas $\Delta \varepsilon_{1, \mathrm{NO}_{3}}$ shows no visible trend.

The slope and intercept of the plot in Fig. 2 give values of $\Delta \varepsilon_{2, \mathrm{NO}_{3}}=-0.37 \pm 0.13 \mathrm{~kg} \mathrm{~mol}^{-1}$ and $\log _{10} \beta_{2, \mathrm{NO}_{3}}^{0}=2.29 \pm 0.64$ respectively in the temperature range 293-298 $\mathrm{K}$, which are consistent with analogous values for uranium(Iv), for which $\Delta \varepsilon_{2, \mathrm{NO}_{3}}=-0.41 \mathrm{~kg} \mathrm{~mol}^{-1}$ and $\log _{10} \beta_{2, \mathrm{NO}_{3}}^{0}=2.30^{45}$ and plutonium(Iv), for which $\Delta \varepsilon_{2, \mathrm{NO}_{3}}=-0.36 \mathrm{~kg} \mathrm{~mol} \mathrm{~m}^{-1}$ and $\log _{10} \beta_{2, \mathrm{NO}_{3}}^{0}=3.66^{47}$ - once again suggesting that the approach of Fig. 1 and 2 is reasonable.

Using the $\Delta \varepsilon$ and $\beta^{0}$ values obtained above, $\log _{10} \beta$ vs. $I$ plots can be constructed for the mono and bisnitrato $\mathrm{Np}$ (Iv) complexes using eqn (8) and (9), Fig. 3. Both plots in Fig. 3 have forms typical of a SIT curve: a decrease in stability constant with increasing $I$ at low ionic strength due to the attenuation of long range electrostatic attractions, and an increase in stability constant with increasing $I$ at high ionic strength due to the increasing dominance of non-electrostatic short range attractive interactions. ${ }^{29}$

As discussed above, of the $\mathrm{Np}(\mathrm{Iv})$-hydroxide complexes, only the monohydroxide is expected to be present under conditions studied here. ${ }^{44}$ The literature gives $\mathrm{Np}$ (Iv) monohydroxide complex SIT coefficient values at $298 \mathrm{~K}$ of $-0.36 \mathrm{~kg} \mathrm{~mol}^{-1}$ and -1.23 for $\Delta \varepsilon_{1, \mathrm{OH}}$ and $\log _{10} K_{1, \mathrm{OH}}^{0}$, respectively. ${ }^{44,48}$ Accordingly, Fig. 4 shows a graph of $\log _{10} K_{1, \mathrm{OH}}$ vs. $I$ from 0.10-1.0 mol kg ${ }^{-1} \mathrm{HNO}_{3}$ calculated using eqn (10). The upper limit of $I$ derives from uncertainties from ionic strength corrections in the calculation of $\Delta \varepsilon_{1, \mathrm{OH}}$ and $\log _{10} K_{1, \mathrm{OH}}^{0}$ in the source literature - which make the use of the derived parameters at

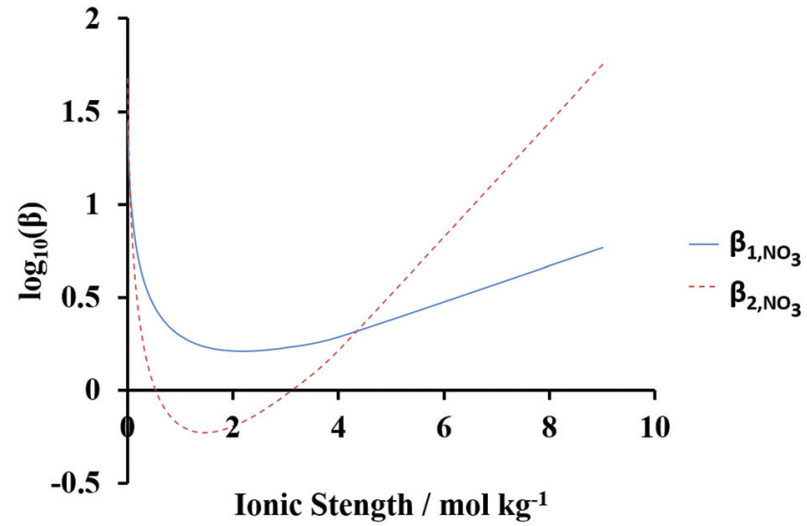

Fig. 3 Graph of $\log _{10} \beta$ versus ionic strength for $\mathrm{NpNO}_{3}{ }^{3+}$ and $\mathrm{Np}$ $\left(\mathrm{NO}_{3}\right)_{2}{ }^{2+}$ complexes calculated using eqn (8) \& (9) in the temperature range $293-298 \mathrm{~K}$.

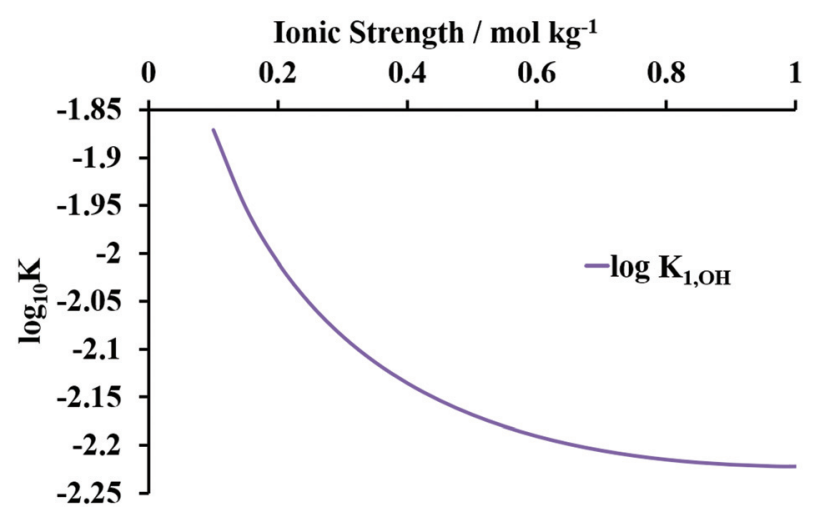

Fig. 4 Graph of $\log _{10} K_{1, \mathrm{OH}}$ versus ionic strength at $298 \mathrm{~K}$ for the $\mathrm{NpOH}^{3+}$ complex calculated using eqn (10).

$I>1.0 \mathrm{~mol} \mathrm{~kg}^{-1}$ unreliable. $^{48}$ Thus, in subsequent speciation calculations, values of $K_{1, \mathrm{OH}}^{0}$ at $I<1.0 \mathrm{~mol} \mathrm{~kg}{ }^{-1}$ are calculated as per Fig. 4 ; at $I>1 \mathrm{~mol} \mathrm{~kg}^{-1}$, the stability constants calculated at $1.0 \mathrm{~mol} \mathrm{~kg}^{-1}$ are used as default.

Modelling $\mathrm{HNO}_{3}$ partial dissociation (eqn (11)) in solutions at high $\left[\mathrm{HNO}_{3}\right]$ improves both speciation and kinetic model accuracy by accounting for the effect of (i) proton concentration on ligand hydrolysis rates and $\mathrm{Np}$ (Iv) hydroxamate concentration; and (ii) free nitrate ion concentration on nitrato complex speciation and concentration. ${ }^{49}$

$$
\mathrm{HNO}_{3}+\mathrm{H}_{2} \mathrm{O} \stackrel{K_{\mathrm{HNO}_{3}}}{\longleftrightarrow} \mathrm{H}_{3} \mathrm{O}^{+}+\mathrm{NO}_{3}{ }^{-} \mathrm{p} K_{\mathrm{A}, \mathrm{HNO}_{3}}=-1.44
$$

Thus, Fig. 5 shows a speciation diagram for the $\mathrm{Np}(\mathrm{IV})-\mathrm{NO}_{3}$ system as a function of total $\mathrm{HNO}_{3}$, calculated to allow for both $\mathrm{HNO}_{3}$ partial dissociation (eqn (11)) and ionic strength derived variations in stability/formation constant values for $\mathrm{NpOH}^{3+}, \mathrm{NpNO}_{3}{ }^{3+}$ and $\mathrm{Np}\left(\mathrm{NO}_{3}\right)_{2}{ }^{2+}$ (via eqn (8)-(10) and Fig. 4). Two observations can be made.

(i) It can be seen from Fig. 5 that under the conditions employed in the kinetic experiments described below i.e. 


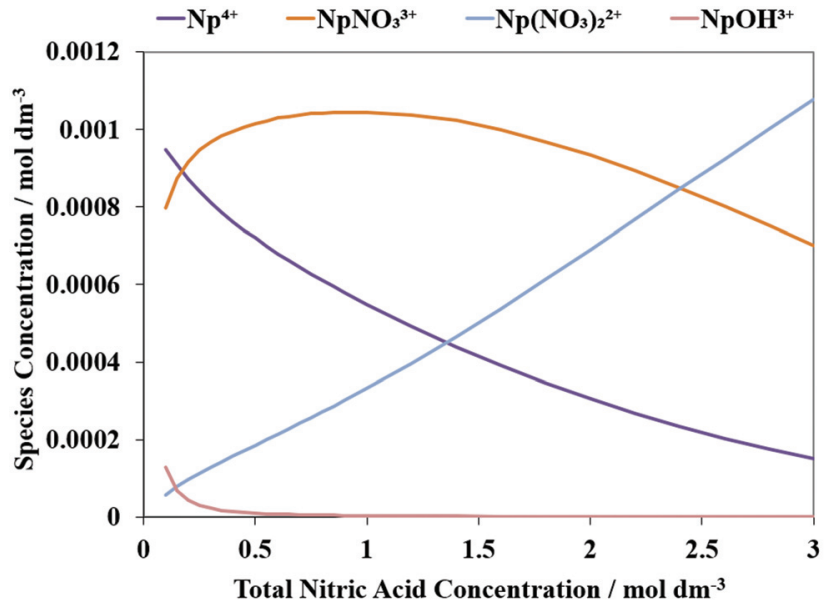

Fig. 5 Speciation diagram of $0.0019 \mathrm{~mol} \mathrm{dm}^{-3} \mathrm{~Np}$ (Iv) in solutions of $0.10-3.0 \mathrm{~mol} \mathrm{dm}^{-3} \mathrm{HNO}_{3}, T=293-298 \mathrm{~K}$.

$\left[\mathrm{HNO}_{3}\right]>0.50 \mathrm{~mol} \mathrm{dm}{ }^{-3}$, the $\mathrm{NpOH}^{3+}$ concentration is negligible compared to that of free $\mathrm{Np}^{4+}$ and the two $\mathrm{Np}(\mathrm{rv})-\mathrm{NO}_{3}$ complexes, so validating our decision above to ignore the higher hydroxide complexes of $\mathrm{Np}(\mathrm{Iv})$ in our speciation calculations.

(ii) Not unexpectedly, Fig. 5 shows that at $\left[\mathrm{HNO}_{3}\right]>$ $\sim 0.30 \mathrm{~mol} \mathrm{dm}^{-3}, \mathrm{~Np}$ (Iv) solution speciation is dominated by nitrate complexes. In particular, the concentration of the $\mathrm{Np}\left(\mathrm{NO}_{3}\right)^{3+}$ complex dominates at $\left[\mathrm{HNO}_{3}\right]>\sim 0.2 \mathrm{~mol} \mathrm{dm}^{-3}$ and quickly rises to a maximum value at $\left[\mathrm{HNO}_{3}\right]=\sim 1 \mathrm{~mol} \mathrm{dm}^{-3}$. The apparent abruptness of this rise is likely due to the speciation in Fig. 5 being reported not as a function of $\left[\mathrm{H}_{3} \mathrm{O}^{+}\right]$or $\left[\mathrm{NO}_{3}{ }^{-}\right]$individually, but rather as a function of increasing total $\left[\mathrm{HNO}_{3}\right]$ - for which both $\left[\mathrm{H}_{3} \mathrm{O}^{+}\right]$and $\left[\mathrm{NO}_{3}{ }^{-}\right]$increase at the same time. Consequently, the equilibrium positions of the reactions given by eqn (5) $\left(\mathrm{NpOH}^{3+}\right.$ formation) and eqn (7) (mononitrato complex formation) both move simultaneously: eqn (7) to the left and eqn (5) to the right. The combined effect of these two concurrent shifts in equilibrium with increasing $\left[\mathrm{HNO}_{3}\right]$ is to synergistically increase the concentration of $\mathrm{Np}\left(\mathrm{NO}_{3}\right)^{3+}$ in the manner observed at $\left[\mathrm{HNO}_{3}\right]<1 \mathrm{~mol} \mathrm{dm}{ }^{-3}$.

With these two observations in mind, calculations can now be extended to include $\mathrm{Np}(\mathrm{Iv})$ complexation by AHA. Accordingly, Fig. 6-8 shows speciation diagrams, calculated using the data of Table 1 and eqn (8)-(11), for the Np(rv)-AHA$\mathrm{HNO}_{3}$ system showing $\mathrm{Np}$ (Iv) speciation as a function of $\mathrm{pHL}$ at total $\mathrm{HNO}_{3}$ concentrations relevant to the kinetic experiments described below i.e. $\left[\mathrm{HNO}_{3}\right]=0.50,1.0$ and $3.0 \mathrm{~mol} \mathrm{dm}^{-3}$. Whilst the hydrolysis of the $\mathrm{Np}(\mathrm{Iv})$ ions to form the monohydroxide complex is explicitly included in our model via eqn (10), it is noteworthy that $\mathrm{NpOH}^{3+}$ is negligibly nearzero in the speciation diagrams of Fig. 6-8, even at the lowest total [AHA] of $1 \times 10^{-3} \mathrm{~mol} \mathrm{dm}^{-3}(\mathrm{pHL}=3)$ and lowest total $\left[\mathrm{HNO}_{3}\right]$ of $0.5 \mathrm{~mol} \mathrm{dm}{ }^{-3}$ used in the computation of Fig. 6 . The latter is especially surprising as Fig. 5 shows that, in the absence of AHA and at the total Np(rv) concentrations of $1.93 \times$ $10^{-3} \mathrm{~mol} \mathrm{dm}^{-3}$ under discussion here, $\mathrm{NpOH}^{3+}$ is present at a

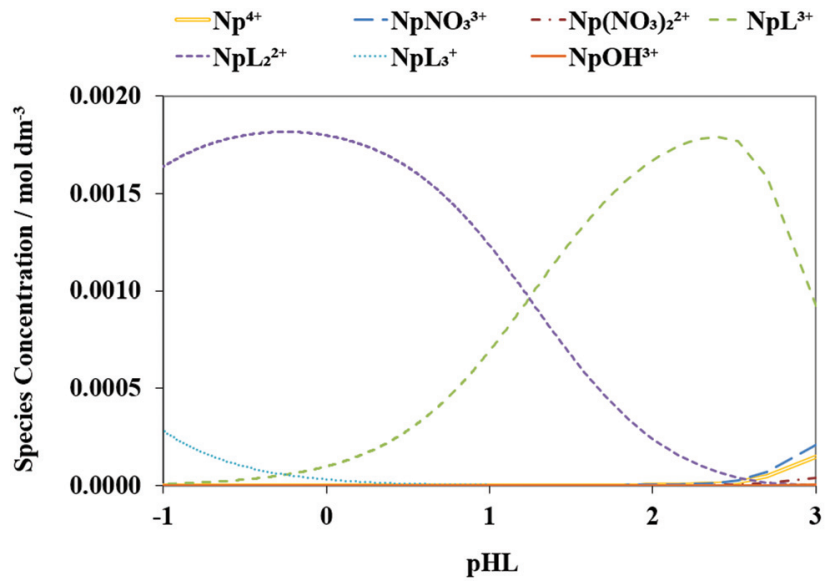

Fig. 6 Speciation diagram for the $\mathrm{Np}$ (Iv) AHA system at $295 \mathrm{~K}$ showing concentrations of $\mathrm{Np}^{4+}, \mathrm{NpNO}_{3}{ }^{3+}, \mathrm{Np}\left(\mathrm{NO}_{3}\right)_{2}{ }^{2+}, \mathrm{NpL}^{3+}, \mathrm{NpL}_{2}{ }^{2+}, \mathrm{NpL}_{3}{ }^{3+}$ and $\mathrm{NpOH}^{3+}$ as functions of total AHA concentration (expressed as $\mathrm{pHL}$ ) calculated at total $[\mathrm{Np}(\mathrm{Iv})]=0.00193 \mathrm{~mol} \mathrm{dm}{ }^{-3}$ and $\left[\mathrm{HNO}_{3}\right]=0.5 \mathrm{~mol} \mathrm{dm}^{-3}$, $\mathrm{pH}=0.30$.

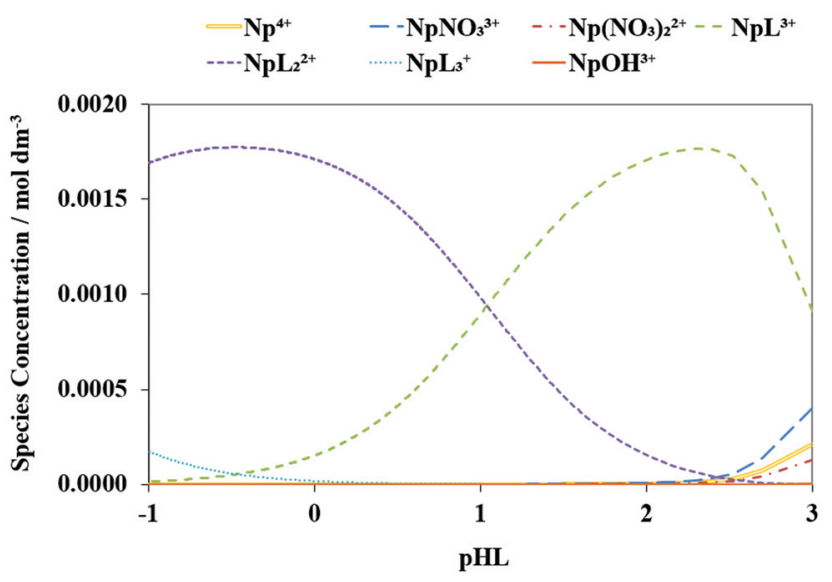

Fig. 7 Speciation diagram for the $\mathrm{Np}(\mathrm{IV}) \mathrm{AHA}$ system at $295 \mathrm{~K}$ showing concentrations of $\mathrm{Np}^{4+}, \mathrm{NpNO}_{3}{ }^{3+}, \mathrm{Np}\left(\mathrm{NO}_{3}\right)_{2}{ }^{2+}, \mathrm{NpL}^{3+}, \mathrm{NpL}_{2}{ }^{2+}, \mathrm{NpL}_{3}{ }^{3+}$ and $\mathrm{NpOH}^{3+}$ as functions of total AHA concentration (expressed as $\mathrm{pHL}$ ) calculated at total $[\mathrm{Np}(\mathrm{Iv})]=0.00193 \mathrm{~mol} \mathrm{dm} \mathrm{m}^{-3}$ and $\left[\mathrm{HNO}_{3}\right]=1 \mathrm{~mol} \mathrm{dm}^{-3}$, $\mathrm{pH}=0$.

concentration of $<2 \times 10^{-5} \mathrm{~mol} \mathrm{dm}^{-3}$ in $0.5 \mathrm{~mol} \mathrm{dm}^{-3}$ nitric acid. This suggests that $\mathrm{Np}(\mathrm{Iv})$ ion hydrolysis is effectively suppressed by AHA complexation under the conditions studied here, an observation that is in agreement with the work of Sarsfield et al. on the extraction of Np(rv)-AHA complexes into TBP and who likewise conclude that hydrolysis is suppressed, except at very low AHA and $\mathrm{HNO}_{3}$ concentrations of 0.01 and $0.1 \mathrm{~mol} \mathrm{dm}^{-3}$ respectively. ${ }^{28}$

It is widely held that hydrolysis of free hydroxamic acids and hydroxamate ligands in mono- and bishydroxamate complexes occurs via nucleophilic attack on the carbonyl carbon, ${ }^{43}$ ultimately producing carboxylic acid and hydroxylamine. Previously, we have applied this mechanism to analysis of the hydrolysis of the monoformohydroxamate-neptunium(Iv) 


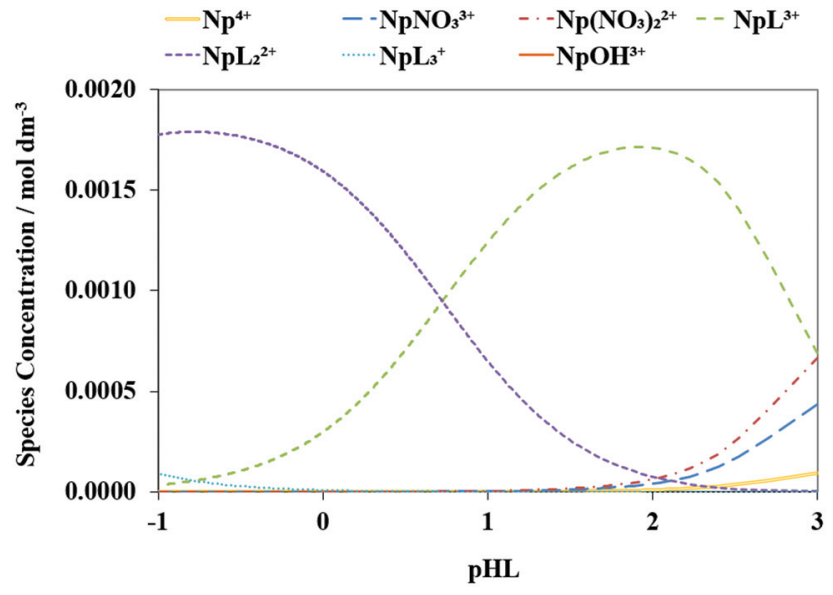

Fig. 8 Speciation diagram for the $\mathrm{Np}$ (IV) AHA system at $295 \mathrm{~K}$ showing concentrations of $\mathrm{Np}^{4+}, \mathrm{NpNO}_{3}{ }^{3+}, \mathrm{Np}\left(\mathrm{NO}_{3}\right)_{2}{ }^{2+}, \mathrm{NpL}^{3+}, \mathrm{NpL}_{2}{ }^{2+}, \mathrm{NpL}_{3}{ }^{3+}$ and $\mathrm{NpOH}^{3+}$ as functions of total AHA concentration (expressed as $\mathrm{pHL}$ ) calculated at total $[\mathrm{Np}(\mathrm{IV})]=0.00193 \mathrm{~mol} \mathrm{dm}^{-3}$ and $\left[\mathrm{HNO}_{3}\right]=3.0 \mathrm{~mol}$ $\mathrm{dm}^{-3}, \mathrm{pH}=-0.48$.

complex. ${ }^{4}$ Here we extend this approach to the hydrolysis of the acetohydroxamate ligand in the Np(Iv) mono- and bisacetohydroxamate complexes for the first time. In this analysis, the newly developed speciation diagrams of Fig. 6-8 are used to define the initial concentrations of the kinetic runs analysed. This is the subject of the next section.

\section{Kinetic studies of the $\mathrm{Np}$ (Iv) AHA system}

The equations for the hydrolysis of free AHA and hydroxamate ligands in the mono- and bis-hydroxamate-neptunium(Iv) complexes at $25^{\circ} \mathrm{C}$ are as follows:

$$
\mathrm{HL}+\mathrm{H}_{3} \mathrm{O}^{+} \stackrel{k_{0}}{\longrightarrow} \mathrm{CH}_{3} \mathrm{COOH}+\mathrm{NH}_{3} \mathrm{OH}^{+}
$$

where

$$
\begin{aligned}
& k_{0}=1.8 \times 10^{-5} \mathrm{dm}^{3} \mathrm{~mol}^{-1} \mathrm{~s}^{-1} \\
& \mathrm{NpL}^{3+}+2 \mathrm{H}_{3} \mathrm{O}^{+} \stackrel{k_{1}}{\longrightarrow} \mathrm{Np}^{4+}+\mathrm{CH}_{3} \mathrm{COOH}+\mathrm{NH}_{3} \mathrm{OH}^{+}+\mathrm{H}_{2} \mathrm{O} \\
& \mathrm{NpL}_{2}{ }^{2+}+2 \mathrm{H}_{3} \mathrm{O}^{+} \stackrel{k_{2}}{\longrightarrow} \mathrm{NpL}^{3+}+\mathrm{CH}_{3} \mathrm{COOH}+\mathrm{NH}_{3} \mathrm{OH}^{+}+\mathrm{H}_{2} \mathrm{O}
\end{aligned}
$$

Given that the $\mathrm{p} K_{\mathrm{a}, \mathrm{AHA}}$ of AHA varies from 9.54 to 8.96 for ionic strength values from 0 to $3 \mathrm{~mol} \mathrm{~kg}^{-1}$ (see Table 1 and the data of ref. 21 and 50 then under the conditions employed in the experiments described below, $\mathrm{pH} \leq 0, I \geq 0.5 \mathrm{~mol} \mathrm{~kg}^{-1}$ ), the dominant form of the free ligand will be the acid rather than the depronated conjugate base. Thus, direct hydrolysis of the free hydroxamate anion may be neglected. However, the hydrolysis of the free hydroxamic acid itself, and the associated decrease in total AHA concentration with time, must be included and this is accounted for via eqn (12).

The hydrolysis of free AHA and bound hydroxamate both occur via a second order process in which free acid and bound hydroxamate are protonated during the rate determining step to form the reducible intermediate, ${ }^{4,7}$ yielding the following rate equations

$$
\begin{gathered}
-\frac{d[\mathrm{HL}]}{\mathrm{d} t}=k_{0}[\mathrm{HL}]\left[\mathrm{H}_{3} \mathrm{O}^{+}\right] \\
-\frac{d\left[\mathrm{NpL}^{3+}\right]}{\mathrm{d} t}=k_{1}\left[\mathrm{NpL}^{3+}\right]\left[\mathrm{H}_{3} \mathrm{O}^{+}\right] \\
-\frac{d\left[\mathrm{NpL}_{2}^{2+}\right]}{\mathrm{d} t}=k_{2}\left[\mathrm{NpL}_{2}{ }^{2+}\right]\left[\mathrm{H}_{3} \mathrm{O}^{+}\right]
\end{gathered}
$$

The main purpose of this work then, is to determine values of $k_{1}$ and $k_{2}$ from experimental kinetic hydrolysis data in the context of the reaction scheme of eqn (13) and (14). Parameter estimation is the process of determining a set of unknown model (fitting) parameters by optimisation of computed fits to experimental data. Here, the experimental data are a series of kinetic runs for the Np(Iv)-AHA system during which the concentrations of the hydrolysing complexes were followed by UVvis spectrophotometry, Fig. 9 and 10. The gPROMS software package contains a parameter estimation function which can then be used to compute fits for absorbance vs. time data extracted from Fig. 10 and so determine values of the chosen (model) fitting parameters.

For the spectrophotometric data of Fig. 10, the fitting parameters used were the rate constants $k_{1}$ and $k_{2}$, and the UV-vis extinction coefficients for the mono and bis complexes, which were unknown a priori in the first instance, the extinction coefficients of $\mathrm{Np}^{4+}, \mathrm{NpNO}_{3}{ }^{3+}, \mathrm{Np}\left(\mathrm{NO}_{3}\right)_{2}{ }^{2+}$ and $\mathrm{NpOH}^{3+}$ were determined either from the work of Yusov et al. ${ }^{44}$ or from the UV-visible, near-IR EAS of solutions of $\mathrm{Np}$ (Iv) in AHA-free

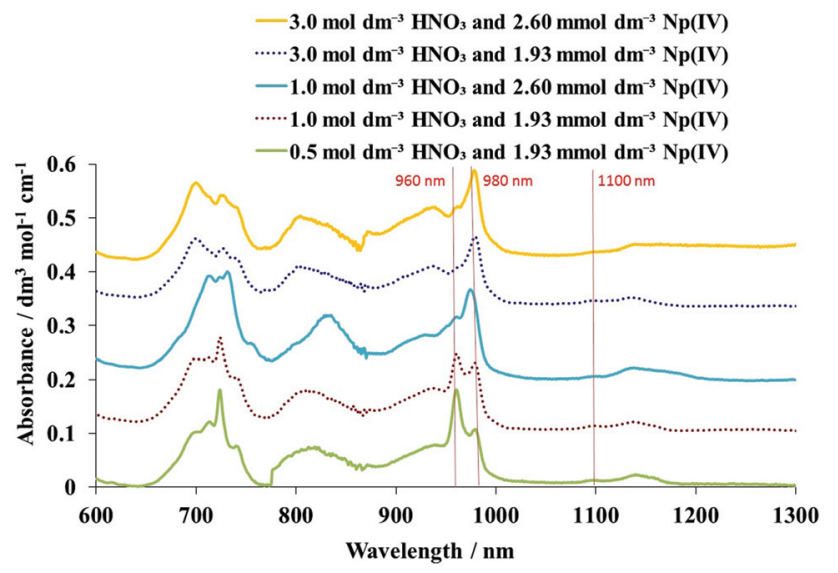

Fig. 9 Electronic absorbance spectra of $1.93 \mathrm{mmol} \mathrm{dm}^{-3}$ neptunium(iv) in $0.50 \mathrm{~mol} \mathrm{dm}^{-3}, 1.0 \mathrm{~mol} \mathrm{dm}^{-3}$ and $3.0 \mathrm{~mol} \mathrm{dm}^{-3} \mathrm{HNO}_{3}$, and $2.6 \mathrm{mmol} \mathrm{dm}^{-3}$ neptunium(Iv) in $1.0 \mathrm{~mol} \mathrm{dm}^{-3}$ and $3.0 \mathrm{~mol} \mathrm{dm}^{-3} \mathrm{HNO}_{3}$ recorded at 297-298 K. The spectra are offset for clarity; working from the top spectrum to the bottom, the samples from which they were taken contain the following amounts of $\mathrm{Np}(\mathrm{v})$ : $0.3,0.27,0.3,0.27$ and $0.27 \mathrm{mmol} \mathrm{dm}^{-3}$ respectively. As described in the main text, $\mathrm{Np}(\mathrm{v})$ and its associated nitrato complexes are treated as silent in the deconvolution of contributions made by the $\mathrm{Np}$ (Iv) species (free and nitrato complexes) to the peak at $732 \mathrm{~nm}$. 

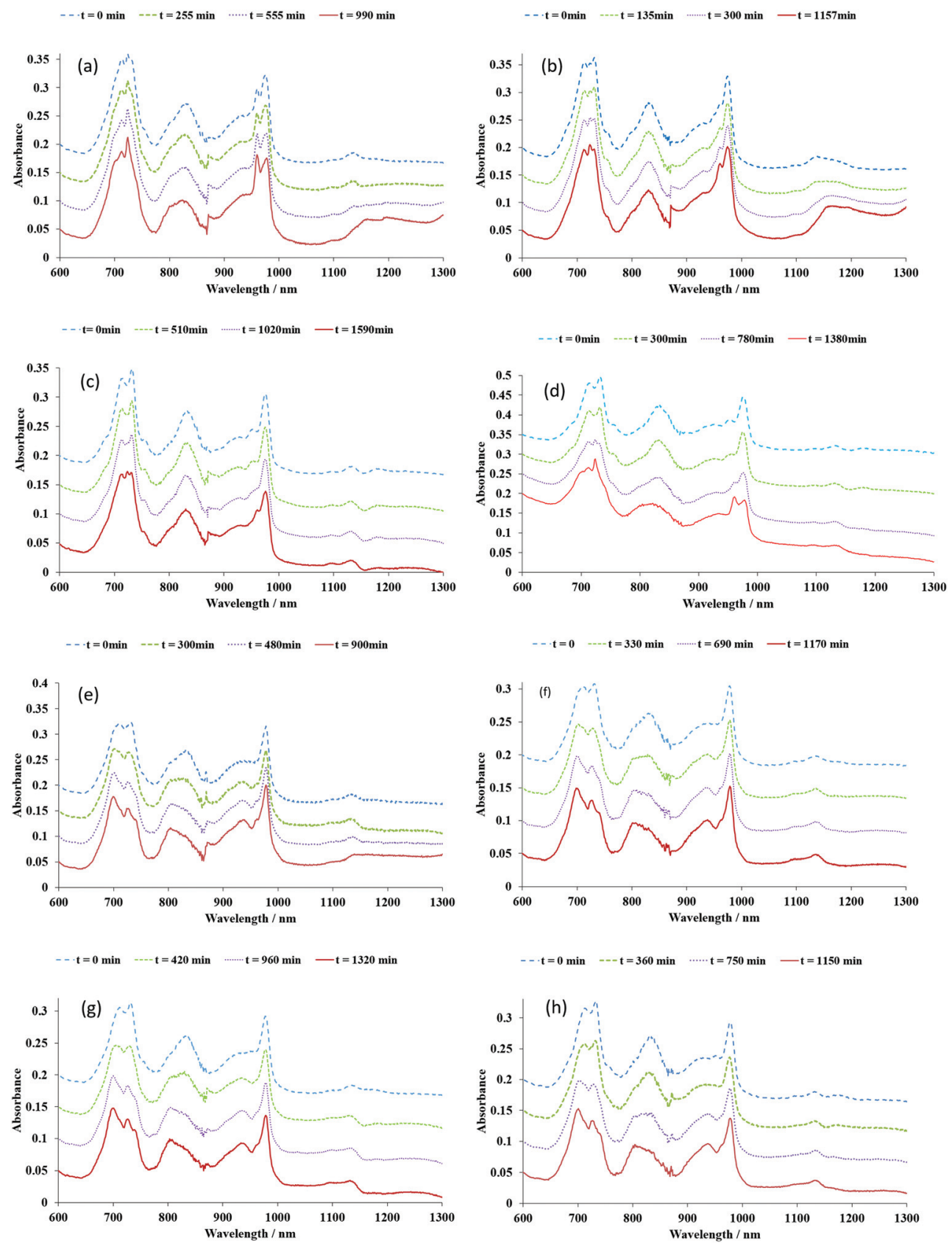

Fig. 10 Electronic absorbance spectra recorded as a function of time at 297-298 K during kinetic run studies of the Np(Iv)-AHA system for the following initial total acid, $\mathrm{AHA}$ and $\mathrm{Np}(\mathrm{Iv})$ concentrations: (a) $\left[\mathrm{HNO}_{3}\right]=1 \mathrm{~mol} \mathrm{dm}^{-3}$, $[\mathrm{AHA}]=5.26 \mathrm{mmol} \mathrm{dm}^{-3},\left[\mathrm{~Np}^{4+}\right]=2.80 \mathrm{mmol}^{-3} \mathrm{dm}^{-3} ;(\mathrm{b})\left[\mathrm{HNO}_{3}\right]=$ $1 \mathrm{~mol} \mathrm{dm}^{-3},[\mathrm{AHA}]=10 \mathrm{mmol} \mathrm{dm}{ }^{-3},\left[\mathrm{~Np}^{4+}\right]=2.60 \mathrm{mmol} \mathrm{dm}{ }^{-3}$; (c) $\left[\mathrm{HNO}_{3}\right]=1 \mathrm{~mol} \mathrm{dm}^{-3},[\mathrm{AHA}]=50 \mathrm{mmol} \mathrm{dm}^{-3},\left[\mathrm{~Np}^{4+}\right]=1.95 \mathrm{mmol} \mathrm{dm}^{-3}$; (d) $\left[\mathrm{HNO}_{3}\right]=1 \mathrm{~mol} \mathrm{dm}{ }^{-3},[\mathrm{AHA}]=100 \mathrm{mmol} \mathrm{dm}{ }^{-3},\left[\mathrm{~Np}^{4+}\right]=1.93 \mathrm{mmol} \mathrm{dm}^{-3}$; (e) $\left[\mathrm{HNO}_{3}\right]=3 \mathrm{~mol} \mathrm{dm}^{-3},[\mathrm{AHA}]=37.5 \mathrm{mmol} \mathrm{dm}^{-3},\left[\mathrm{~Np}^{4+}\right]=2.60 \mathrm{mmol}^{4}$ $\mathrm{dm}^{-3}$; (f) $\left[\mathrm{HNO}_{3}\right]=3 \mathrm{~mol} \mathrm{dm}{ }^{-3},[\mathrm{AHA}]=50 \mathrm{mmol} \mathrm{dm}^{-3},\left[\mathrm{~Np}^{4+}\right]=1.93 \mathrm{mmol} \mathrm{dm}^{-3} ;$ (g) $\left[\mathrm{HNO}_{3}\right]=3 \mathrm{~mol} \mathrm{dm}^{-3},[\mathrm{AHA}]=100 \mathrm{mmol} \mathrm{dm}^{-3},\left[\mathrm{~Np}^{4+}\right]=$ $1.93 \mathrm{mmol} \mathrm{dm}^{-3}$; (h) $\left[\mathrm{HNO}_{3}\right]=3 \mathrm{~mol} \mathrm{dm}{ }^{-3}$, [AHA] $=250 \mathrm{mmol} \mathrm{dm}{ }^{-3},\left[\mathrm{~Np}^{4+}\right]=1.93 \mathrm{mmol} \mathrm{dm}{ }^{-3}$. Depending upon starting conditions, $2.5 \%-52 \%$ of $\mathrm{Np}(\mathrm{IV})$ is initially present as $\mathrm{NpL}_{2}{ }^{2+}$. Spectra are offset for clarity. As described in the main text, $\mathrm{Np}(\mathrm{v})$ and its weak AHA complexes are treated as silent in the deconvolution of contributions made by $\mathrm{Np}$ (Iv) species (free, nitrato and AHA complexes) to the peak at $732 \mathrm{~nm}$.

$\mathrm{HNO}_{3}$ shown in Fig. 9. The total Np concentration used in each EAS was in the range 2.2 to $3.1 \mathrm{mmol} \mathrm{dm}^{-3}$; the majority of this was present as $\mathrm{Np}(\mathrm{Iv})$ (see Experimental section above), although the bands seen at 979 and $1100 \mathrm{~nm}$ in all spectra of Fig. 9 indicates the presence of some $\mathrm{Np}(\mathrm{v})$. Quantification of these bands using their molar absorptivities of 369 and 24 $\mathrm{dm}^{3} \mathrm{~mol}^{-1} \mathrm{~cm}^{-1}$ respectively ${ }^{32}$ (vide supra) indicates that the concentration of $\mathrm{Np}(\mathrm{v})$ in these experiments has a mean value of $0.3 \mathrm{mmol} \mathrm{dm}^{-3}$, no more than $13 \%$ of total Np and nearly an order of magnitude less than the majority constituent, $\mathrm{Np}(\mathrm{Iv})$. The $\log _{10} \beta$ values for the formation of the mononitrato complex of $\mathrm{Np}(\mathrm{v})$ at an ionic strength of $2 \mathrm{~mol} \mathrm{dm}^{-3}$ is 
reported to be in the range -0.25 to -1.6 ; that for the formation of the bisnitrato complex is reported to be -1.37 . Comparison of these values with $\log _{10} \beta$ values, calculated in Fig. 3, of +0.21 and -0.21 for the formation of mono and bisnitrato complexes of $\mathrm{Np}$ (Iv) at an ionic strength of $2 \mathrm{~mol} \mathrm{dm}^{-3}$ indicates that, thermodynamically, formation of the mononitrato neptunium(Iv) complex is at least 3 and potentially 70 times more likely than formation of the mononitrato neptunium(v) complex; formation of the bisnitrato neptunium(Iv) complex is similarly 15 times more likely than that of the bisnitrato neptunium(v) complex. Given that the concentration of $\mathrm{Np}$ (Iv) in the experiments of Fig. 9 is nearly 10 times that of $\mathrm{Np}(\mathrm{v})$, these figures indicate that the concentration of the mononitrato neptunium(v) complex is at most 3.3\% that of the mononitrato neptunium(Iv) complex in these systems, whilst that of the bisnitrato neptunium(v) complex is $<0.7 \%$ that of the bisnitrato neptunium(Iv) species. It is, therefore, reasonable to conclude that the experiments of Fig. 9 are dominated by the speciation of the $\mathrm{Np}(\mathrm{Iv})$-nitrate complexes and that, once the total $\mathrm{Np}$ (Iv) concentration in each experiment has been corrected for the total $\mathrm{Np}(\mathrm{v})$ concentration, the effect of $\mathrm{Np}(\mathrm{v})$ can be ignored.

Thus, Fig. 9 shows the spectra of 1.9 and $2.6 \mathrm{mmol} \mathrm{dm}^{-3}$ solutions of $\mathrm{Np}$ (Iv) in $1.0 \mathrm{~mol} \mathrm{dm}{ }^{-3}$ and $3.0 \mathrm{~mol} \mathrm{dm}{ }^{-3} \mathrm{HNO}_{3}$ in the presence of an effectively silent $\sim 0.3 \mathrm{mmol} \mathrm{dm}^{-3}$ of $\mathrm{Np}(\mathrm{v})$. For each of the spectra of Fig. 9, the concentrations of $\mathrm{Np}^{4+}$, $\mathrm{NpNO}_{3}{ }^{3+}$ and $\mathrm{Np}\left(\mathrm{NO}_{3}\right)_{2}{ }^{2+}$ for each solution were calculated using SIT theory-based speciation diagrams of the type shown in Fig. 5. Using Beer's law, these concentrations were then equated to the background-corrected absorbance (see section 2) at $732 \mathrm{~nm}$ by the unknown extinction coefficients for $\mathrm{NpNO}_{3}{ }^{3+}$ and $\mathrm{Np}\left(\mathrm{NO}_{3}\right)_{2}{ }^{2+}$ and a value for the extinction coefficient of $\mathrm{Np}^{4+}$ at $732 \mathrm{~nm}$ of $31 \mathrm{dm}^{3} \mathrm{~mol}^{-1} \mathrm{~cm}^{-1}-$ the latter value obtained from data reported by Yusov et al. ${ }^{44}$

From Fig. 5, it can be seen that there are insignificant quantities of $\mathrm{NpOH}^{3+}$ in solution under the acid conditions used in the experiments of Fig. 9 and 10 below; therefore, we took the view that this species does not require fitting in the remainder of the work described here. The resultant simultaneous equations for the absorbances at $732 \mathrm{~nm}$ of $\mathrm{NpNO}_{3}{ }^{3+}$ and $\mathrm{Np}$ $\left(\mathrm{NO}_{3}\right)_{2}{ }^{2+}$ were then solved using Microsoft equation solver, yielding extinction coefficient values of 55.1 and 24.5 $\mathrm{dm}^{3} \mathrm{~mol}^{-1} \mathrm{~cm}^{-1}$, respectively.

Kinetic hydrolysis experiments were then conducted on the $\mathrm{Np}$ (Iv)-AHA system as a function of $\mathrm{HNO}_{3}$ concentration at fixed AHA concentration and as a function of AHA concentration at fixed $\mathrm{HNO}_{3}$ concentration, results shown in Fig. 10 which itself is a summary of a much larger data set.

Whilst the focus of these experiments is the hydrolysis kinetics of the $\mathrm{Np}$ (Iv)-AHA system, the spectra of Fig. 10 exhibit similar absorption bands at 979 and $1100 \mathrm{~nm}$ to those seen in Fig. 9, indicating the presence of $\mathrm{Np}(\mathrm{v})$. Analysis of these band at $t=0$ as per Fig. 9 indicates that this again corresponds to initial concentrations of $\mathrm{Np}(\mathrm{v})$ in the range 0.26 to $0.3 \mathrm{mmol} \mathrm{dm}^{-3}$ i.e. $12 \%$ of total neptunium present.

Taylor et al. have reported $\log _{10} \beta$ values of 4.83 and 8.09 for the formation of the mono- and bisacetohydroxamato com- plexes of $\mathrm{Np}(\mathrm{v})$ in $2 \mathrm{~mol} \mathrm{dm}{ }^{-3}$ perchlorate media at $293 \mathrm{~K}^{23}$ As per Table 1, these can be converted to conditional equilibrium constants for mono- and bisacetohydroxamato $\mathrm{Np}(\mathrm{v})$ complex formation of $6.4 \times 10^{-5}$ and $1.7 \times 10^{-6}$ respectively. Comparison of these with the values for the analogous parameters for $\mathrm{Np}$ (Iv), $K_{1}$ and $K_{2}$, given in Table 1 shows that, thermodynamically, formation of $\mathrm{Np}(\mathrm{v})$-AHA complexes is at least seven orders of magnitude less likely than Np(Iv)-AHA complexes. $\mathrm{Np}(\mathrm{v})$-AHA complex formation can therefore be ignored in the experiments of Fig. 10. Further, comparison of the 979 and $1100 \mathrm{~nm}$ bands obtained at the start and end of the runs shown in Fig. 10 indicates that the $\mathrm{Np}(\mathrm{v})$ concentration is nearly invariant during each run; typically it is found to change by $\sim 23 \mu \mathrm{mol} \mathrm{dm}{ }^{-3}$, corresponding to an uncertainty in the total $\mathrm{Np}$ (Iv) concentration of only $1 \%$ which, given that $\mathrm{Np}$ (Iv) is the focus of these experiments, can be safely neglected. Thus, as in the treatment of the data of Fig. 9, it is reasonable to conclude that the data of Fig. 10 are dominated by the hydrolysis behaviour of the Np(Iv)-AHA system and that, once the total $\mathrm{Np}$ (Iv) concentration in the each experiment has been corrected for the total $\mathrm{Np}(\mathrm{v})$ concentration, the effect of $\mathrm{Np}(\mathrm{v})$ can be ignored.

Rates of hydrolysis of AHA within the Np(Iv)-AHA system were then determined from the data for Fig. 10 (and its associated larger dataset) by first measuring the absorbance of free Np(Iv), mono- and bis-hydroxamato and mono- and bisnitrato complexes at $732 \mathrm{~nm}$ as a function of time. The resultant absorbance $v s$. time plots are shown in Fig. 11a-h. gPROMSmodelled absorbance-time curves, also shown in Fig. 11a-h, were then computed as described above by using the (previously unknown) Beer-Lambert extinction coefficients for the $1: 1$ and $2: 1 \mathrm{~Np}$ (Iv)-AHA complexes and the kinetic rate parameters $k_{1}$ and $k_{2}$ as fitting parameters. In contrast, the values of extinction coefficients of the $\mathrm{Np}^{4+}, \mathrm{NpNO}_{3}{ }^{3+}, \mathrm{Np}\left(\mathrm{NO}_{3}\right)_{2}{ }^{2+}$ complexes (vide supra) and the conditional equilibrium constants $K_{1}, K_{2}, K_{3}$, (given by eqn (4a)-(4c) and Table 1) $\beta_{1, \mathrm{NO}_{3}}, \beta_{2}$, $\mathrm{NO}_{3}$ (given by SIT calculations using eqn (8) and (9)) and the $\mathrm{p} K_{\mathrm{A}, \mathrm{HNO}_{3}}$ value for nitric acid (given by eqn (11)) were fixed. The value of $k_{0}$, the rate constant for the hydrolysis of the free AHA ligand was also fixed by taking the average of the values of $2.7 \times 10^{-5} \mathrm{dm}^{3} \mathrm{~mol}^{-1} \mathrm{~s}^{-1}$ and $3.2 \times 10^{-5} \mathrm{dm}^{3} \mathrm{~mol}^{-1} \mathrm{~s}^{-1}$ computed using the Arrhenius data of Chung and Lee ${ }^{26}$ and Taylor et $a{ }^{27}{ }^{27}$ respectively.

Fig. 11a-h show good agreement between experimental and modelled absorbance data, with the gPROMS-estimated values of the rate parameters $k_{1}$ and $k_{2}$ used to obtain the model-toexperiment data fits being summarised in Table 4 . The mean values for the rate constants for the hydrolysis of the monoand bis-hydroxamate complexes are found to be $k_{1}=3.5 \times 10^{-5}$ $\pm 2.5 \times 10^{-5} \mathrm{dm}^{3} \mathrm{~mol}^{-1} \mathrm{~s}^{-1}$ and $k_{2}=1.9 \times 10^{-3} \pm 1.3 \times 10^{-3}$ $\mathrm{dm}^{3} \mathrm{~mol}^{-1} \mathrm{~s}^{-1}$ respectively at $298 \mathrm{~K}$. These are both more than the value of $k_{0}$ of $3 \times 10^{-5} \mathrm{dm}^{3} \mathrm{~mol}^{-1} \mathrm{~s}^{-1}$ used in the gPROMs fitting procedure of Fig. 11 and Table 4 , the value for $k_{2}$ substantially so. This indicates a progression of order:

$$
k_{2}>k_{1}>k_{0}
$$



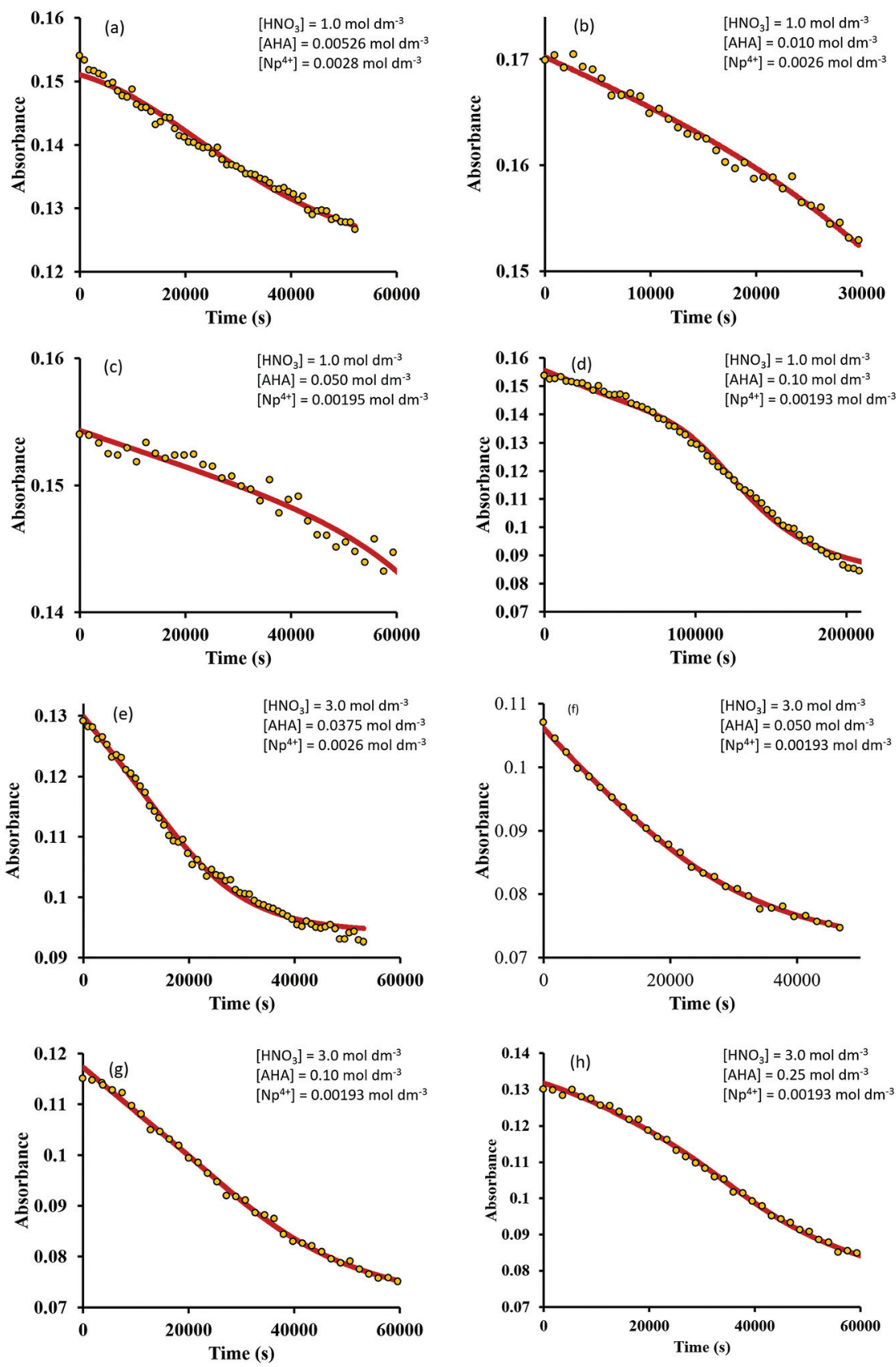

Fig. 11 Plots of experimental and modelled absorbance of the Np(IV)-AHA system at $732 \mathrm{~nm}$, data of (a-h) taken from the corresponding figures (and respective associated larger spectral data sets) in Fig. 10. For the avoidance of doubt, initial total acid, AHA and Np(Iv) concentrations are shown as insets on each figure.

That is, acetohydroxamate in the $2: 1$ AHA-Np(Iv) complex hydrolyses much faster than acetohydroxamate in the 1:1 complex which hydrolyses faster than free AHA. This is consistent with the findings of our earlier studies of the Fe(III)-AHA system wherein the rate of hydrolysis of the ligand within the monohydroxamato-iron(III) complex was greater than that of the free hydroxamate, this complexation induced enhancement in hydrolysis rate becoming more pronounced with increasing temperature. , $^{3,51}$
This was explained in the context of a quantum mechanical calculation-based analysis which showed that the hydrolysis of the free hydroxamic acid proceeds via the energetically favoured protonation of the carbonyl group followed by nucleophilic attack of a water molecule on the carbonyl carbon. This leads to the cleavage of the $\mathrm{C}-\mathrm{N}$ bond, and the formation of $\mathrm{NH}_{2} \mathrm{OH}$ as the leaving group. ${ }^{51}$ The same calculations suggest that, for hydroxamic acids bound to metal centres, it is protonation of the less favourable nitrogen site that results in a 
Table 4 Experimental conditions and fitted rate constant values for $k_{1}$ and $k_{2}$ for the hydrolysis of the monohydroxamatoneptunium(iv) complex and the bishydroxamatoneptunium(Iv) complex at $298 \mathrm{~K}$. Using eqn (1), the value of $k_{0}$ was fixed at $3.0 \times 10^{-5} \mathrm{dm}^{3} \mathrm{~mol}^{-1} \mathrm{~s}^{-1}$

\begin{tabular}{|c|c|c|c|c|c|c|c|c|}
\hline $\begin{array}{l}\text { Experiment } \\
\text { of Fig. } 10 \\
\text { and } 11\end{array}$ & $\begin{array}{l}{\left[\mathrm{HNO}_{3}\right] /} \\
\mathrm{mol} \mathrm{dm}^{-3}\end{array}$ & $\begin{array}{l}{\left[\mathrm{Np}^{4+}\right] /} \\
\mathrm{mol} \mathrm{dm}^{-3}\end{array}$ & $\begin{array}{l}{[\mathrm{AHA}]_{\mathrm{o}} /} \\
\mathrm{mol} \mathrm{dm}^{-3}\end{array}$ & $\begin{array}{l}\% \mathrm{~Np} \text { initially } \\
\text { as } \mathrm{NpL}_{2}^{2+}\end{array}$ & $\begin{array}{l}\text { Fitted } k_{1} / \\
\mathrm{dm}^{3} \mathrm{~mol}^{-1} \mathrm{~s}^{-1}\end{array}$ & $\begin{array}{l}\text { Fitted } k_{2} / \\
\mathrm{dm}^{3} \mathrm{~mol}^{-1} \mathrm{~s}^{-1}\end{array}$ & $\begin{array}{l}\text { Fitted extinction } \\
\text { coefficient for } \\
\mathrm{NpL}^{3+} \text { at } 732 \mathrm{~nm} / \\
\mathrm{dm}^{3} \mathrm{~mol}^{-1} \mathrm{~cm}^{-1}\end{array}$ & $\begin{array}{l}\text { Fitted extinction } \\
\text { coefficient for } \\
\mathrm{NpL}_{2}{ }^{2+} \text { at } 732 \mathrm{~nm} / \\
\mathrm{dm}^{3} \mathrm{~mol}^{-1} \mathrm{~cm}^{-1}\end{array}$ \\
\hline A & 1.0 & 0.0028 & 0.00526 & 2.5 & $4.6 \times 10^{-5}$ & & 58 & \\
\hline B & 1.0 & 0.0026 & 0.010 & 6.8 & $4.9 \times 10^{-5}$ & & 65 & \\
\hline $\mathrm{C}$ & 1.0 & 0.00195 & 0.050 & 33 & $6.9 \times 10^{-5}$ & $5.3 \times 10^{-5}$ & 77 & 85 \\
\hline D & 1.0 & 0.00193 & 0.10 & 50 & $2.6 \times 10^{-5}$ & $4.5 \times 10^{-4}$ & 74 & 87 \\
\hline $\mathrm{E}$ & 3.0 & 0.0026 & 0.0375 & 14 & $6.9 \times 10^{-5}$ & $1.8 \times 10^{-3}$ & 45 & 89 \\
\hline $\mathrm{F}$ & 3.0 & 0.00193 & 0.050 & 19 & $1.9 \times 10^{-6}$ & $3.0 \times 10^{-3}$ & 52 & 74 \\
\hline G & 3.0 & 0.00193 & 0.10 & 34 & $1.3 \times 10^{-5}$ & $2.2 \times 10^{-3}$ & 55 & 74 \\
\hline $\mathrm{H}$ & 3.0 & 0.00193 & 0.25 & 52 & $1.0 \times 10^{-5}$ & $3.8 \times 10^{-3}$ & 61 & 74 \\
\hline \multicolumn{5}{|c|}{ Mean values of fitted parameters } & $\begin{array}{l}3.5 \times 10^{-5} \pm \\
2.5 \times 10^{-5}\end{array}$ & $\begin{array}{l}1.9 \times 10^{-3} \pm \\
1.3 \times 10^{-3}\end{array}$ & $61 \pm 10$ & $81 \pm 6.6$ \\
\hline
\end{tabular}

weakening of the $\mathrm{C}-\mathrm{N}$ bond, which enables the hydrolysis to proceed via the ejection of a NHOH-M leaving group, with the electron withdrawing effect of the metal centre making the nucleophilic attack by water on the carbonyl carbon more likely. It is the latter effect which is principally responsible for the greater rate of hydrolysis of the bound hydroxamate compared to the free AHA.

That a similar trend in rate parameters to that seen in the $\mathrm{Fe}($ III)-AHA system is also observed in the Np(Iv)-AHA system suggests that a similar mechanism of hydrolysis enhancement is in operation with the electron withdrawing effect of the neptunium(Iv) metal centre increasing the susceptibility of the carbonyl carbon to nucleophilic attack, thus explaining why $k_{1}>k_{0}$.

A value of $k_{1}$ for the monohydroxamato-iron(III) complex of $5.3 \times 10^{-5} \mathrm{dm}^{3} \mathrm{~mol}^{-1} \mathrm{~s}^{-1}$ at $298 \mathrm{~K}$ can be obtained using the Arrhenius data of our earlier study. This is larger than the value of $3.8 \times 10^{-5} \mathrm{dm}^{3} \mathrm{~mol}^{-1} \mathrm{~s}^{-1}$ obtained here for the analogous $k_{1}$ parameter for the monohydroxamato-neptunium(rv) complex at the same temperature (see Table 4). This hierarchy of $k_{1}$ values can be simply understood on the basis of the charge densities of the two ions. Using Shannon-Prewitt effective ionic radii values, charge densities of 427 and $162 \mathrm{C}$ $\mathrm{mm}^{-3}$ can be calculated for high spin $\mathrm{Fe}^{3+}$ and 8-coordinate $\mathrm{Np}^{4+}$ respectively. $\mathrm{Fe}(\mathrm{III})$ will therefore have a stronger electron withdrawing effect than $\mathrm{Np}(\mathrm{Iv})$ when complexed to the $\mathrm{O}$ atom of the hydroxamate carbonyl, with a consequent greater enhancement in the rate of nucleophilic attack of water on the $\mathrm{C}$ atom of the carbonyl.

Table 4 and eqn (18) also indicate that the rate constant for the hydrolysis of the hydroxamate ligand on the bishydroxamato-Np(Iv) complex, $k_{2}$, is greater than that for the same ligand on the monohydroxamato-Np(rv) complex, $k_{1}$. Since protonation of the hydroxamate nitrogen leads to hydrolysis of the complex, this could be explained simply in terms of there being two hydroxamate ligands attached to the metal centre in the bishydroxamato complex - with the likelihood of protonation and subsequent nucleophilic attack on a carbonyl carbon consequently increased with respect to the monohydroxamato complex.
However, $k_{2}$ is almost two orders of magnitude greater than $k_{1}$, compared to $k_{1}$ being only $\sim 20 \%$ greater than $k_{0}$. Whilst this unambiguously demonstrates that complexation with $\mathrm{Np}(\mathrm{Iv})$ increases the rate of hydrolysis of AHA, the size of the difference between $k_{2}$ and $k_{1}$ compared to that between $k_{1}$ and $k_{0}$ suggests other factors are in play beyond a simple mass action effect derived from having two ligand per bishydroxamato versus one per monohydroxamato complex. One possible source of the increased value of $k_{2}$ versus $k_{1}$ is the charge on the complex to which the hydrolyzing ligand is attached. The monohydroxamato complex has a net charge of +3 , whilst the bishydroxamato complex has a lower net charge of +2 . Given that a key step in the hydrolysis of the bound ligand is protonation of the hydroxamate nitrogen site, coulombic repulsion issues may arise from the positive charges on the protonating $\mathrm{H}^{+}$ion and the complex. With its lower net charge, the bishydroxamato complex might be expected to protonate more easily than the monohydroxamato complex and thus hydrolyse more quickly, so leading to the observed increase in $k_{2}$ over $k_{1}$.

It is worth discussing one final point with regards to eqn (18). That $k_{1}$ is greater than $k_{0}$ for the $\mathrm{Np}(\mathrm{Iv})$-AHA system is the opposite of the trend we have previously reported for the analogous rate parameters in the Np(rv)-FHA system. ${ }^{4}$ This is most likely due to the fact that, in the then-absence of stability constant data for the Np(Iv)-FHA system, Np(rv)-AHA speciation diagrams were used to inform the design of the $\mathrm{Np}$ (Iv)FHA kinetic run experiments and the subsequent interpretation of the results. Here, not only have $\mathrm{Np}$ (Iv)-AHA speciation diagrams been used to inform interpretation of $\mathrm{Np}$ (Iv)-AHA kinetic run data - those diagrams have also been calculated using ionic strength dependent conditional stability constants; the approach adopted here is thus more self-consistent and the results, therefore, more reliable.

Returning to Table 4, the extinction coefficient values for $\mathrm{NpL}^{3+}$ and $\mathrm{NpL}_{2}{ }^{2+}$ at $732 \mathrm{~nm}$ are currently unknown and these were also used as model fitting parameters for the data of Fig. 11a-h (vide supra) - the so-obtained values also being shown in Table 4. Mean values of these extinction coefficients obtained using the whole data set of Table 3 are $61.2 \pm 10$ 
(16\% variation) and $80.5 \pm 6.6(8 \%$ variation $) \mathrm{dm}^{3} \mathrm{~mol}^{-1} \mathrm{~cm}^{-1}$ for $\mathrm{NpL}^{3+}$ and $\mathrm{NpL}_{2}{ }^{2+}$ respectively.

Closer inspection of the data reveals that different mean extinction coefficients for both $\mathrm{NpL}^{3+}$ and $\mathrm{NpL}_{2}{ }^{2+}$ may be calculated at the two $\mathrm{HNO}_{3}$ concentrations employed in the kinetic run experiments. At $1.0 \mathrm{~mol} \mathrm{dm}{ }^{-3} \mathrm{HNO}_{3}$, mean extinction coefficients of $68.5 \pm 7.5$ (11\% variation) and $86 \pm 1(1.1 \%$ variation) $\mathrm{dm}^{3} \mathrm{~mol}^{-1} \mathrm{~cm}^{-1}$ may be calculated for $\mathrm{NpL}^{3+}$ and $\mathrm{NpL}_{2}{ }^{2+}$ respectively, whilst at $3.0 \mathrm{~mol} \mathrm{dm}{ }^{-3} \mathrm{HNO}_{3}$ mean extinction coefficients of $53.25 \pm 5.7$ (11\% variation) and $77.75 \pm 6.5$ (8.3\% variation) $\mathrm{dm}^{3} \mathrm{~mol}^{-1} \mathrm{~cm}^{-1}$ may be calculated for $\mathrm{NpL}^{3+}$ and $\mathrm{NpL}_{2}{ }^{2+}$ respectively.

This observed difference in the mean extinction coefficients calculated for each complex at these two acidities is almost certainly due to the effect of ionic strength on the conditional equilibrium constants $K_{1}$ and $K_{2}$. Similar nitric acid concentration-dependent variations in the extinction coefficients for Am(III), Am(v) and Am(VI) at 503, 718 and $996 \mathrm{~nm}$ respectively are reported by Grimes et al. ${ }^{52}$ using values previously reported by Zalupski et $a .^{53}$ Mean values over a nitric acid concentration range of 1 to $6.5 \mathrm{~mol} \mathrm{dm}^{-3}$ are found to be $342 \pm 46$ (13.5\% variation), $40 \pm 4.2$ (11\% variation) and $85 \pm 6$ (7\% variation) $\mathrm{dm}^{3} \mathrm{~mol}^{-1} \mathrm{~cm}^{-1}$ for the Am(III), Am(v) and Am(VI) peaks respectively - variations that are consistent with those reported here. Grimes et al. attribute their observed acid dependent variations in extinction coefficients to the media effects of increasing or decreasing background electrolyte concentrations when $\left[\mathrm{HNO}_{3}\right]$ is varied.

Such an effect for $\mathrm{Np}(\mathrm{Iv})$-AHA complexes can also be expected on the basis of the variations with ionic strength of $\beta_{1}$ and $\beta_{2}$ for $\mathrm{Np}(\mathrm{Iv})$-nitrate complexes shown in Fig. 3. However, whilst we were able to account for the ionic strengthderived variations in stability constants for the $\mathrm{Np}$ (Iv)-nitrate system by use of the SIT relationships of eqn (11) and (12), there is no available analogous SIT data for the acetohydroxamate complexes of $\mathrm{Np}(\mathrm{Iv})$. This is due to the limited number of acidities at which $K_{1}$ and $K_{2}$ have been measured. Thus, full correction of the extinction coefficients reported in Table 4 in the context of SIT theory is not currently possible.

\section{Conclusions}

We propose a new, coupled thermodynamic and kinetic model for the hydrolysis of AHA in the Np(Iv)-AHA system. This model is used to fit hydrolytic kinetic run data for the Np(Iv)AHA system using the custom modelling software package, gPROMS. The model includes not only the hydrolysis of the $1: 1$ and $2: 1$ AHA-Np(Iv) complexes, but also the ionic strength dependent concentrations of $\mathrm{NpNO}_{3}{ }^{3+}, \mathrm{Np}\left(\mathrm{NO}_{3}\right)_{2}{ }^{2+}$ and $\mathrm{NpOH}^{3+}$ determined using SIT theory. In doing this, we have calculated speciation diagrams for the same $\mathrm{Np}(\mathrm{Iv})-$ nitrate and $\mathrm{Np}(\mathrm{Iv})-\mathrm{OH}$ complexes as a function of total nitric acid concentration (i.e. simultaneous variation of both the $\mathrm{H}^{+}$ and $\mathrm{NO}_{3}{ }^{-}$concentration), the first time that this has been done.
Speciation diagrams for the $\mathrm{Np}$ (Iv)- $\mathrm{HNO}_{3}-\mathrm{AHA}$ system indicate that at $\mathrm{pH} \leq 0$, only $\mathrm{Np}^{4+}, \mathrm{NpL}^{3+}, \mathrm{NpL}_{2}{ }^{2+}, \mathrm{NpNO}_{3}{ }^{3+}$ and $\mathrm{Np}\left(\mathrm{NO}_{3}\right)_{2}{ }^{2+}$ are present in significant quantities under the experimental conditions studied here. Modelling of kinetic run experiments using the extinction coefficients and hydrolysis rate constants, $k_{1}$ and $k_{2}$ for the mono- and bis-hydroxamato complexes as fitting parameters gives excellent fits that are self-consistent and give average values of $k_{1}=3.5 \times 10^{-5} \pm 2.5 \times$ $10^{-5} \mathrm{dm}^{3} \mathrm{~mol}^{-1} \mathrm{~s}^{-1}$ and $k_{2}=1.9 \times 10^{-3} \pm 1.3 \times 10^{-3} \mathrm{dm}^{3} \mathrm{~mol}^{-1}$ $\mathrm{s}^{-1}$ respectively at $298 \mathrm{~K}-$ the first time that these have been reported.

These values indicate a hierarchy of AHA hydrolysis rate constants in the order $k_{2}>k_{1}>k_{0}$, indicating that complexation of $\mathrm{Np}$ (Iv) with AHA increases the rate of ligand hydrolysis. Subsequent extension of these modelling approaches to $\mathrm{Pu}(\mathrm{IV})$ ions would then provide a sound basis to understand fully the stability of hydroxamic acids and their actinide complexes in, inter alia, advanced PUREX and UREX process flow sheets. This will be the subject of our next communication.

\section{Conflicts of interest}

There are no conflicts to declare.

\section{Acknowledgements}

The authors wish to thank the Engineering and Physical Science Research Council UK for provision of an EngD award to support Scott Edwards, The National Nuclear Nuclear Laboratory, Sellafield Ltd and The Lloyds Register Foundation for additional financial support. The Lloyds Register Foundation is an independent charity that supports the advancement of engineering-related education, and funds research and development that enhances safety of life at sea, on land and in the air.

\section{Notes and references}

1 P. D. Wilson, The Nuclear Fuel Cycle: From Ore to Wastes, Oxford University Press, 1996.

2 R. J. Taylor, C. R. Gregson, M. J. Carrott, C. Mason and M. J. Sarsfield, Solvent Extr. Ion Exch., 2013, 31, 442-462.

3 F. P. L. Andrieux, C. Boxall and R. J. Taylor, J. Solution Chem., 2007, 36, 1201-1217.

4 F. P. L. Andrieux, C. Boxall, I. May and R. J. Taylor, J. Solution Chem., 2008, 37(2), 215-232.

5 R. J. Taylor, I. May, A. L. Wallwork, I. S. Denniss, N. J. Hill, B. Y. Galkin, B. Y. Zilberman and Y. S. Fedorov, J. Alloys Compd., 1998, 271-273, 534-537.

6 P. Tkac and A. Paulenova, Sep. Sci. Technol., 2008, 43(9-10), 2670-2683.

7 K. K. Ghosh, Indian J. Chem., Sect. B: Org. Chem. Incl. Med. Chem., 1997, 36, 1089-1102.

8 S. N. Gray, Biochem. Soc. Trans., 1998, 26, 666-670. 
9 S. Pepelinjak, B. Zorc and I. Butula, Acta Pharm., 2005, 55, 401-408.

10 P. Chittari, V. R. Jadhav, K. N. Ganesh and S. Rajappa, J. Chem. Soc., Perkin Trans. 1, 1998, 1319-1324.

11 R. R. Nanewar and U. Tandon, Talanta, 1978, 25(6), 352353.

12 el-R. Kenawy, M. el-Newehy, F. Abdel-Hay and R. M. Ottenbrite, Biomacromolecules, 2007, 8(1), 196-201.

13 F. Vernon, Pure Appl. Chem., 2009, 54, 2151-2158.

14 K. N. Raymond, G. E. Freeman and M. J. Kappel, Inorg. Chim. Acta, 1984, 94, 193-204.

15 J. C. Renshaw, G. D. Robson, A. P. J. Trinci, M. G. Wiebe, F. R. Livens, D. Collison and R. J. Taylor, Mycol. Res., 2002, 106, 1123-1142.

16 B. Monzyk and A. L. Crumbliss, J. Am. Chem. Soc., 1979, 101, 6203-6213.

17 A. L. Crumbliss and J. M. Harrington, in Advances in Inorganic Chemistry, ed. R. van Eldik and C. D. Hubbard, Academic Press, 2009, vol. 61, pp. 179-250.

18 A. M. Albrecht-Gary and A. L. Crumbliss, Met. Ions Biol. Syst., 1998, 35, 239-327.

19 B. Colston, G. R. Choppin and R. J. Taylor, Radiochim. Acta, 2000, 88, 329-334.

20 E.-H. L. Dong-Yong Chung, Bull. Korean Chem. Soc., 2005, 26(11), 1692-1694.

21 R. J. Taylor, C. Mason, R. Cooke and C. Boxall, J. Nucl. Sci. Technol., 2002, 39(sup3), 278-281.

22 M. J. Carrott, O. D. Fox, G. LeGurun, C. J. Jones, C. Mason, R. J. Taylor, F. P. L. Andrieux and C. Boxall, Radiochim. Acta, 2009, 96, 333-343.

23 R. J. Taylor, S. Sinkov, G. R. Choppin and I. May, Solvent Extr. Ion Exch., 2008, 26(1), 41-61.

24 M. J. Carrott, O. D. Fox, C. J. Maher, C. Mason, R. J. Taylor, S. I. Sinkov and G. R. Choppin, Solvent Extr. Ion Exch., 2007, 25(6), 723-745.

25 Advanced Separation Techniques for Nuclear Fuel Reprocessing and Radioactive Waste Treatment, ed. K. L. Nash and G. J. Lumetta, Woodhead Publishing Ltd., 2011.

26 D. Y. Chung and E. H. Lee, J. Ind. Eng. Chem., 2006, 12(6), 962-966.

27 R. J. Taylor and I. May, Czech. J. Phys., 1999, 49(1), 617-621.

28 M. J. Sarsfield, H. E. Sims and R. J. Taylor, Solvent Extr. Ion Exch., 2011, 29, 49-71.

29 I. Grenthe, F. Mompean, K. Spahiu and H. Wanner, Guidelines For The Extrapolation To Zero Ionic Strength, OECD Nuclear Energy Agency, 2013.

30 R. J. Lemire, et al., Chemical Thermodynamics of Neptunium and Plutonium, OECD Nuclear Energy Agency, Elsevier, 2001.
31 M. J. Sarsfield, R. J. Taylor and C. J. Maher, Radiochim. Acta, 2009, 95(12), 677-682.

32 H. A. Friedman and L. M. Toth, J. Inorg. Nucl. Chem., 1980, 42, 1347-1349.

33 L. Alderighi, P. Gans, A. Ienco, D. Peters, A. Sabatini and A. Vacca, Coord. Chem. Rev., 1999, 184(1), 311-318.

34 A. I. Alonso, A. M. Urtiaga, S. Zamacona, A. Irabien and I. Ortiz, J. Membr. Sci., 1997, 130(1-2), 193-203.

35 L. T. Markouska, V. D. Meshko and M. S. Marinkouski, J. Serb. Chem. Soc., 2006, 71(8-9), 957-967.

36 M. I. Ali and P. A. Schneider, Chem. Eng. Sci., 2008, 63(13), 3514-3525.

37 T. Suau, G. Álvaro, M. D. Benaiges and J. López-Santin, Biochem. Eng. J., 2008, 41(1), 95-103.

38 PSE: gPROMS technologies, Model validation and modelbased data analysis http:/www.psenterprise.com/gproms/ technologies/model_validation.html (accessed Mar 4, 2016).

39 Process Systems Enterprise Limited, gPROMS Documentation v3.7. 2013.

40 I. V. Shilin and V. K. Nazarov, Radiokhimiya, 1966, 8, 514519.

41 A. G. Rykov and G. N. Yakovlev, Sov. Radiochem., 1966, 8, 26-30.

42 P. R. Danesi, R. Chiarizia, G. Scibona and G. D'Alessandro, J. Inorg. Nucl. Chem., 1971, 33(10), 3503-3510.

43 Y. A. Barbanel and L. P. Murav'eva, Sov. Radiochem., 1972, 14(3), 498-501.

44 A. B. Yusov, A. M. Fedosseev and C. H. Delegard, Radiochim. Acta, 2004, 92(12), 869-881.

45 I. Grenthe, et al., Chemical Thermodynamics of Uranium, OECD Nuclear Energy Agency, 2004.

46 N. A. Smith and K. R. Czerwinski, J. Radioanal. Nucl. Chem., 2013, 298(3), 1777-1783.

47 J. M. Berg, D. K. Veirs, R. B. Vaughn, M. A. Cisneros and C. A. Smith, J. Radioanal. Nucl. Chem., 1998, 235(1-2), 2529.

48 V. Neck and J. I. Kim, Radiochim. Acta, 2001, 89(1), 1-16.

49 E. Wiberg and N. Wiberg, Inorganic Chemistry, Academic Press, 2001.

50 The Chemistry of Hydroxylamines, Oximes and Hydroxamic Acids, ed Z. Rappoport and J. F. Liebman, John Wiley \& Sons, 2008.

51 F. P. L. Andrieux, C. Boxall, H. M. Steele and R. J. Taylor, J. Solution Chem., 2014, 43(3), 608-622.

52 T. S. Grimes, G. P. Horne, C. J. Dares, S. M. Pimblott, S. P. Mezyk and B. J. Mincher, Inorg. Chem., 2017, 56(14), 8295-8301.

53 P. R. Zalupski, T. S. Grimes and C. R. Heathman, Appl. Spectrosc., 2017, 21(12), 2608-2615. 